\title{
Ekmeklik Buğday Genotiplerinin Erzurum Koşullarında Tane Verimi ve Verim Unsurları Yönünden Değerlendirilmesi
}

\author{
Sinan BAYRAM ${ }^{*}$, Ali ÖZTÜRK², Murat AYDIN² \\ ${ }^{1}$ GAP Uluslararası Tarımsal Araştırma ve Eğitim Merkezi, 21110, Diyarbakır, Türkiye \\ ${ }^{2}$ Atatürk Üniversitesi, Ziraat Fakültesi, Tarla Bitkileri Bölümü, 25240, Erzurum, Türkiye \\ *e-mail: sinan.bayram@tarim.gov.tr; Tel: +90 (412) 326 1323/104; Fax: +90 (412) 3261324
}

Özet: $\mathrm{Bu}$ araştırma, Erzurum ekolojik koşullarına uygun ve yüksek verimli çeşitlerin belirlenmesi amacıyla 2009-10 ve 2010-11 ürün yıllarında 64 ekmeklik buğday genotipi ile tesadüf blokları deneme planına göre yürütülmüştür. Tane verimi ve verim unsurları yönünden genotipler arasındaki farkların önemli olduğu belirlenmiştir. Ürün yıllarının ortalamasına göre $\mathrm{m}^{2}$ 'deki başak sayısı 495.6-875.6, başaktaki tane sayısı 13.726.6, 1000 tane ağırlığı 28.9-43.3 g, tane verimi ise 213.5-756.8 kg/da arasında değişim göstermiştir. En yüksek tane verimi Demir $2000(756.8 \mathrm{~kg} / \mathrm{da})$ çeşidinden elde edilmiş, bu çeşidi Atl1 $2002(756.3 \mathrm{~kg} / \mathrm{da})$, Karahan 99 $(710.1 \mathrm{~kg} / \mathrm{da})$, Doğu $88(708.8 \mathrm{~kg} / \mathrm{da})$ ve Türkmen $(701.5 \mathrm{~kg} / \mathrm{da})$ çeşitleri izlemiş̧tir. Tane verimi ile $\mathrm{m}^{2}$ 'deki başak sayısı $\left(\mathrm{r}=0,640^{* * *}\right)$, başaktaki tane sayısı $\left(\mathrm{r}=0,545^{* * *}\right)$ ve bin tane ağırlığı $\left(\mathrm{r}=0,333^{* *}\right)$ arasındaki ilişkilerin olumlu ve önemli olduğu belirlenmiştir. İncelenen karakterlerin kendi aralarında ve genotipler ile olan ilişkilerini görsel olarak değerlendirmek amacıyla biplot analiz yöntemi kullanılmış, en stabil genotiplerin Atlı 2002, Doğu 88, İzgi 2001, Harmankaya 99 ve Karasu 90; en ideal genotiplerin ise Atlı 2002, Doğu 88, İzgi 2001, Lancer ve Türkmen olduğu belirlenmiştir. Araştırma sonucunda, Atlı 2002 ve İzgi 2001 çeşitlerinin, yörede daha önceki araştırmalarda yüksek verim istikrarı ile dikkat çeken Doğu 88 çeşidine alternatif olabileceği belirlenmiştir.

Anahtar kelimeler: Biplot analizi, Ekmeklik buğday, Tane verimi, Verim unsurları

\section{Evaluation of Yield Components and Grain Yield of Bread Wheat Genotypes in Erzurum Conditions}

\begin{abstract}
This research was carried out according to the randomized blocks experimental desing with 64 wheat genotypes in 2009-10 and 2010-11 crop years, to determine varieties suitable for Erzurum ecological conditions and high-yield. It was determined significant differences in respect to grain yield and yield components in this study. According to average of product years, it ranged 495.6-875.6 in spike number per $\mathrm{m}^{2}, 13.7-26.6$ in grain number per spike, 28.9-43.3 $\mathrm{g}$ in thousand grain weight and $213.5-756.8 \mathrm{~kg} \mathrm{da}^{-1}$ in-grain yield. The highest grain yields were obtained from Demir 2000 (756.8 $\left.\mathrm{kg} \mathrm{da}^{-1}\right)$, Atl 2002 (756.3 kg da $)$, Karahan 99 (710.1 kg da-1), Doğu $88\left(708.8 \mathrm{~kg} \mathrm{da}^{-1}\right)$ and Türkmen $\left(701.5 \mathrm{~kg} \mathrm{da}^{-1}\right)$, respectively. It was determined that the relationship between grain yield and the spike number per $\mathrm{m}^{2}(\mathrm{r}=0,640 * * *)$, grain number per spike $(\mathrm{r}=0,545 * * *)$ and thousand grain weight $(\mathrm{r}=0,333 * *)$ were positive and significant. Biplot analysis method was applied in order to visually evaluate relationships with other features of investigated features and genotypes. It was determined that the most stable genotypes are Atl 12002, Doğu 88, İzgi 2001, Harmankaya 99 and Karasu 90; that the most ideal genotypes are Atlı 2002, Doğu 88, İzgi 2001, Lancer and Türkmen. As a result of the research, it was determined that the Atlı 2002 and İzgi 2001 cultivars could be an alternative to the Doğu 88 cultivar which attract attention with the high yield stability in the previous researches in the region.
\end{abstract}

Keywords: Biplot analysis, Bread wheat, Grain yield, Yield components

\section{Giriş}

Buğday, 2014 yılı verilerine göre dünyada üretimi yapılan kültür bitkileri arasında ekim alanı bakımından ilk sırada, üretim miktarı ve verim bakımından ise mısır ve çeltikten sonra üçüncü sırada yer almaktadır (FAO 2017). Ülkemizde 2016 yılı verilerine göre 76.719 .448 da ekim alanı ve 20.600.000 ton üretimi (TÜİK 2017) ile kültür bitkileri içerisinde ilk sırada yer alan buğday, Erzurum yöresinde de önemli bir yere sahiptir. Erzurum ilindeki ekili tarla arazisi 3.460.757da, buğday ekim alanı 1.139.722 da, buğday verimi ise $173 \mathrm{~kg} / \mathrm{da}$ 'dır (TÜİK 2017). İldeki birim alan verimi, zaten düşük olan Türkiye ortalamasının $(269 \mathrm{~kg} / \mathrm{da})$ bile çok altındadır. Hızlı bir şekilde 
artan nüfusun, parçalanan ve azalan tarım alanlarından elde edilen üretimle yeterli ve dengeli beslenmesi, her geçen gün daha da zorlaşmaktadır. Bu nedenle artan besin ihtiyaçlarının karşılanmasında, bölge ekolojik koşullarına iyi uyum gösteren, verim ve kalite özellikleri iyi olan genotiplerin belirlenmesi büyük önem taşımaktadır.

Tahıllarda tane verimi, $\mathrm{m}^{2}$ 'de başak sayısı, başakta tane sayısı ve tane ağırlığı tarafından belirlenir (Gebeyehou ve ark. 1982; Simane ve ark. 1993; Preiffer ve ark. 2001). Kışlık buğdaylarda tane verimi büyük ölçüde birim alandaki fertil başak sayısıyla belirlenmektedir (Erekul ve Köhn 2006). Öztürk ve Akten (1999), benzer ekolojik koşullarda kışlık buğdaydan daha yüksek verim elde edilebilmesi için, $\mathrm{m}^{2}$ 'de başak sayısı yüksek genotiplerin tercih edilmesi gerektiğini bildirmişlerdir. Birim alandaki potansiyel başak sayısı esas olarak sapa kalkma başlangıcına kadar olan bitki gelişme süreçleri ve çevre koşulları tarafından belirlenir. Bununla birlikte, fertil kardeş sayısını hasada kadar sürdürebilme yeteneği kuru tarım koşullarında tane verimine katkıda bulunan önemli bir özelliktir (Öztürk 1999). Başakta tane sayısı, başak verimini doğrudan etkileyerek birim alandaki tane veriminin de artmasına neden olan önemli verim unsurlarından birisidir (Altınbaş ve Bilgen 1993; Dokuyucu ve ark. 1999; Bilgin ve Korkut 2005). Gebeyehou ve ark. (1982), tane verimine doğrudan etkisi bakımından en yüksek değeri başaktaki tane sayısının gösterdiğini bildirmişlerdir. Bin tane ağırlığı da tahıllarda tane verimini önemli ölçüde etkileyen bir özelliktir (Tosun ve Yurtman 1973; Peterson ve ark. 1992; Korkut ve ark. 1993). Poehlman (1987), tane ağırlığının çevreden etkilenmekle birlikte çeşit özelliği de olabileceğini bildirmiştir. Büyük ve yoğun tanelerde endospermin endosperm olmayan kısma oranı, küçük taneli olanlara göre daha yüksek orandadır (Yağdı 2004). Bu nedenle 1000 tane ağırlığı buğdayda un miktarının tahmin edilmesinde de iyi bir ölçüt olarak ele alınmaktadır. Genetik yapı ve ekolojik faktörler bin tane ağırlığı üzerine etkili iki önemli faktördür (Korkut ve Ünay 1987).

Özellikler arası ilişkileri görsel olarak inceleme ve değerlendirme esasına dayalı GGE biplot analiz yöntemi, birçok özelliği aynı anda görsel açıdan değerlendirme firsatını sağladığı ve seleksiyonda başarıyı etkilediği için bitki 1slahında uygulanan yenilikçi bir yöntem olarak kabul edilmektedir (Yau 1995; Yan ve ark. 2007). Bu analiz metodunda satır ve sütun faktörlerinin hem kendi arasındaki ilişkileri hem de ikili interaksiyonları görsel olarak sergilenebilmektedir (Yan ve Tinker 2006). Biplot analizi ile genotiplerin çok sayıda özellik ve çevrede iki yönlü veri analizi yapılabilmektedir (Yan 2001).

Bu araştırmada, Erzurum ekolojik koşullarında 64 ekmeklik buğday genotipinin verim unsurları ve tane verimi yönünden incelenerek, yöre koşullarına uygun ve yüksek verimli çeşitlerin belirlenmesi amaçlanmıştır.

\section{Materyal ve Yöntem}

Bu araştırma, Atatürk Üniversitesi Ziraat Fakültesi Tarımsal Araştırma ve Yayım Merkezi Müdürlüğü’ne ait 4 numaralı deneme alanında, 2009-10 ve 2010-11 ürün yıllarında yürütülmüştür. Araştırmada bitki materyali olarak toplam 64 ekmeklik buğday genotipi kullanılmıştır. Bu genotiplerin 44'ü 2007 yılı milli çeşit listesinde yer alan ve ülkemizin kuru tarım alanları için önerilen çeşitlerden (kontrol çeşitleri olarak, sulu tarım alanları için önerilen Bezostaja 1 ve Karasu 90), 20'si ise kuru tarım koşullarında daha önce yetiştirilmiş veya halen yetiştirilmekte olan tescilli ve yerel çeşitlerden oluşmaktadır.

Denemenin yürütüldüğü toprakların bazı fiziksel ve kimyasal analiz sonuçları Çizelge 1'de verilmiştir. Sonuçlar; deneme topraklarının tekstür sınıfının killi-tınlı, organik madde oranlarının az, nötr reaksiyonlu, fosfor yönünden orta, potasyum yönünden ise çok zengin olduğunu göstermiştir (Ergene 1993). Araştırmanın yürütüldüğü 200910 ve 2010-11 ürün yılları ile uzun yıllar ortalamasına ait aylık toplam yağışlar, aylık ortalama sıcaklıklar ve aylara göre minimum sıcaklıklar Çizelge 2'de gösterilmiştir. Erzurum iline ait uzun yıllar ortalaması toplam yağış miktarı 395.2 mm'dir. 2009-10 ve 2010-11 ürün yıllarına ait toplam yağış miktarları ise sırası ile 533.2 ve $513.3 \mathrm{~mm}$ olmuştur. Araştırmanın yürütüldüğü ürün yıllarında uzun yıllar ortalamasına göre önemli miktarda fazla yağış düşmüştür. Erzurum'da yıllık ortalama sıcaklık $5.0^{\circ} \mathrm{C}$ 'dir. Araştırmanın yürütüldüğü ürün yılları uzun yıllar ortalamasına göre daha sıcak geçmiştir.

Araştırma, tesadüf blokları deneme planına göre ve 4 tekrarlı olarak yürütülmüştür. Genotipler her blok içerisinde şansa bağlı olarak dağıtılmış, ekim işlemleri toprak hazırlığ 1 yapıllmış nadas araziye 7 Eylül 2009 ve 16 Eylül 2010 tarihlerinde, elle ve her genotip 1 sıra olacak şekilde yapıllmıştır. Bloklar tava haline getirildikten sonra, $6 \mathrm{~kg} / \mathrm{da} \mathrm{N}$ ve $5 \mathrm{~kg} / \mathrm{da} \mathrm{P}_{2} \mathrm{O}_{5}$ olacak şekilde (fosforun tamamı ve azotun yarısı ekimle birlikte, azotun diğer yarısı ise sapa kalkma başlangıcında (Harrel ve ark. 1993) gübrelenmiştir. Daha sonra $1.0 \mathrm{~m}$ uzunluğunda, 3-5 cm derinliğinde ve $20 \mathrm{~cm}$ aralıkla açılan markör sıralarına, $\mathrm{m}^{2}$ 'ye 475 canlı tohum sıklığında ekim yapıllmıştır. Ekim işleminden hemen sonra, homojen çimlenme-çıkış sağlamak amacıyla tavalara su verilmiş, daha sonra sulama yapılmamıştır. Gelişen yabancı otlar elle kontrol edilmiştir. Tam olgunluk döneminde, bitkiler orakla 
hasat edilerek demet haline getirilip tarlada 3 gün süreyle kurumaya bırakılmış, daha sonra parsel biçer-döveri ile harman edilmiştir. Araştırmada, $\mathrm{m}^{2}$ 'deki başak sayısı, başakta tane sayısı, bin tane ağırlı̆̆ ve tane verimi Öztürk (1999)'a göre belirlenmiştir.

Araştırma sonucunda elde edilen verilerin varyans analizleri deneme planına uygun olarak SAS GLM (SAS Inst., Cary, NC) paket programı ile yapılmış, genotiplere ait ortalamaların karşılaştırılmasında Duncan çoklu karşılaştırma testi kullanılmıştır. Verim unsurları ile tane verimi arasındaki ilişkiler basit korelasyon analizi (r) ile belirlenmiştir. Biplot analizleri ise GenStat $14^{\text {th }}$ paket programı kullanılarak yapılmıştır.

Çizelge 1. Deneme topraklarının bazı fiziksel ve kimyasal özellikleri

\begin{tabular}{cccccc}
\hline Yıllar & Tekstür sınıfı & Organik madde $(\%)$ & $\mathbf{P}_{2} \mathbf{O}_{5}(\mathbf{k g} / \mathbf{d a})$ & $\mathbf{K}_{\mathbf{2}} \mathbf{O}(\mathbf{k g} / \mathbf{d a})$ & $\mathbf{p H}$ \\
\hline $2009-10$ & Killi-tın & 1.74 & 6.30 & 203.0 & 7.3 \\
$2010-11$ & Killi-tın & 1.54 & 5.83 & 196.1 & 7.1 \\
\hline
\end{tabular}

Çizelge 2. Erzurum ilinin araştırmanın yürütüldüğü ürün yılları ile uzun yıllar ortalamasına (UYO: 1990-2010) ait bazı iklim verileri*

\begin{tabular}{|c|c|c|c|c|c|c|c|c|}
\hline \multirow{2}{*}{ Aylar } & \multicolumn{3}{|c|}{ Toplam yağıș (mm) } & \multicolumn{3}{|c|}{ Ortalama sicaklık $\left({ }^{\circ} \mathrm{C}\right)$} & \multicolumn{2}{|c|}{ Minimum sıcaklık $\left({ }^{\circ} \mathrm{C}\right)$} \\
\hline & 2009-10 & 2010-11 & UYO & 2009-10 & 2010-11 & UYO & 2009-10 & 2010-11 \\
\hline Eylül & 43.7 & 8.8 & 21.2 & 12.4 & 17.0 & 13.9 & -5.8 & 2.9 \\
\hline Ekim & 51.0 & 72.2 & 45.2 & 8.7 & 9.2 & 7.7 & 3.9 & -4.7 \\
\hline Kasım & 41.4 & 0.0 & 28.5 & 1.8 & 1.8 & -0.1 & -11.8 & -10.3 \\
\hline Aralık & 15.1 & 12.9 & 23.1 & -1.1 & -1.9 & -7.1 & -20.3 & -14.3 \\
\hline Ocak & 52.2 & 23.4 & 16.3 & -4.3 & -8.4 & -10.8 & -33.9 & -22.2 \\
\hline Şubat & 14.8 & 22.3 & 20.4 & -1.8 & -7.7 & -9.2 & -24.1 & -32.2 \\
\hline Mart & 82.2 & 17.1 & 37.3 & 3.1 & -1.5 & -2.7 & -10.0 & -17.7 \\
\hline Nisan & 54.2 & 147.7 & 57.0 & 5.6 & 5.6 & 5.1 & -5.6 & -11.3 \\
\hline Mayıs & 63.6 & 105.2 & 64.6 & 10.4 & 9.6 & 10.4 & -1.1 & 0.8 \\
\hline Haziran & 50.5 & 55.3 & 43.0 & 15.9 & 14.6 & 14.8 & 4.6 & 3.2 \\
\hline Temmuz & 55.5 & 26.6 & 24.6 & 19.5 & 19.6 & 19.0 & 5.5 & 5.9 \\
\hline Ağustos & 9 & 21.8 & 14.1 & 20.3 & 19.4 & 19.3 & 6.6 & 4.1 \\
\hline Toplam & 533.2 & 513.3 & 395.2 & & & & & \\
\hline Ortalama & & & & 7.5 & 6.4 & 5.0 & & \\
\hline
\end{tabular}

*Erzurum Meteoroloji Bölge Müdürlüğü’nün yıllık iklim rasatlarından alınmıştır.

\section{Bulgular ve Tartışma}

Metrekaredeki başak sayısı yönünden buğday genotipleri arasındaki farklar iki ürün yılında ve ürün yılları ortalaması olarak önemli bulunmuştur. Kardeşlenme kapasitesi ve fertil kardeşleri hasada kadar sürdürme yeteneğinin genotiplere göre değişmesi, $\mathrm{m}^{2}$ ' deki başak sayılarının da farklı olmasına neden olmaktadır (Valerio ve ark. 2009).

Birim alandaki potansiyel başak sayısı esas olarak sapa kalkma başlangıcına kadar olan bitki gelişme süreçleri ve çevre koşulları tarafından belirlenmektedir (Öztürk 1999). Bu açıdan incelendiğinde $\mathrm{m}^{2}$ 'deki başak sayısı üzerine ürün yıllarının etkisi de önemli olmuş, genotiplerin ortalaması olarak 2009-10 ürün yılında (741.5), 201011 ürün yılına (719.0) göre daha yüksek başak sayısı belirlenmiştir. Buğday genotiplerinin iklim faktörlerine farklı tepkilerinin bir sonucu olarak $\mathrm{m}^{2}$ 'deki başak sayısı ürün yıllarına göre değişebilmektedir. Genotiplerin, başak sayısı yönünden sıralanışının yıllara göre farklılık göstermesi “genotip x yıl” interaksiyonunun önemli çıkmasına neden olmuştur (Çizelge 3).

Genotiplerin $\mathrm{m}^{2}$ 'deki başak sayıları 2009-10 ürün yılında 550.0-963.8, 2010-11 ürün yılında ise 278.8-903.8 arasında değişim göstermiştir. Metrekarede en yüksek başak sayısına 2009-10 ürün yılında Polatlı Kösesi (963.8) ve Aytın-98 (952.5), 2010-11 ürün yılında ise Koca Buğday (903.8) genotipi sahip olmuştur. Metrekaredeki en düşük başak sayıları 2009-10 ürün yılında Kırik (550.0), Yayla 305 (571.0) ve Nenehatun (607.5); 2010-11 ürün yılında ise Pamukova 97 (278.8), Seri 82 (321.3) ve Doğankent 1 (446.3) çeşitlerinde tespit edilmiştir. Ürün yılları ortalaması olarak m² deki başak sayısı 495.6-875.6 arasında değişim göstermiş, en fazla başağı Aytın 98 (875.6) oluşturmuş, bu çeşidi Doğu 88 (871.3), Kıraç 66 (845.0) ve Harmankaya 99 (836.9) çeşitleri izlemiştir. Metrekarede en düşük başak sayısı ise Pamukova 97 (495.6), Seri 82 (559.4), Kırkpınar 79 (582.5) ve Doğankent 1 (600.6) çeşitlerinde tespit edilmiş, bu sonuç, kışa dayanıklılığı zayıf olan bu çeşitlerde 2010-11 ürün yılında kış zararına bağlı bitki ölümlerinden kaynaklanmıştır. Nitekim kışlık ekimlerde $\mathrm{m}^{2}$ 'deki fertil başak sayısının 
y1ldan yıla değiş̧ebileceği ve kışı sert geçen yerlerde başak sayılarının daha düşük olabileceği bildirilmiştir (Walker ve Matthews 1991).

Erzurum koşullarında Öztürk ve Akkaya (1996) tarafindan 397.5-609.4 adet, Çağlar ve ark. (2006) tarafindan 373.8-604.4 adet olarak belirlenen $\mathrm{m}^{2}$ 'deki başak sayıları dikkate alındığında araştırmada kullanılan buğday genotiplerimizin bu karakter yönünden daha geniş bir aralıkta varyasyon gösterdiği ve daha yüksek değere sahip olduğu söylenebilir.

Çizelge 3. Buğday genotiplerinin 2009-10 ve 2010-11 ürün yılları ile ürün yıllarının ortalaması olarak $\mathrm{m}^{2}$ 'deki başak ve başaktaki tane sayıları

\begin{tabular}{|c|c|c|c|c|c|c|c|}
\hline \multirow{2}{*}{ No } & \multirow{2}{*}{ Genotip } & \multicolumn{3}{|c|}{ Metrekaredeki başak sayısı (adet) } & \multicolumn{3}{|c|}{ Başaktaki tane sayısı (adet) } \\
\hline & & $2009-10$ & 2010-11 & Ortalama & 2009-10 & 2010-11 & Ortalama \\
\hline 1 & Aksel 2000 & $717.5 \mathrm{~g}-\mathrm{r}$ & $782.5 \mathrm{a}-\mathrm{f}$ & 750.0 a-m & $17.1 \mathrm{a}-\mathrm{h}$ & $23.7 \mathrm{~h}-\mathrm{s}$ & $20.4 \mathrm{f}-\mathrm{o}$ \\
\hline 2 & Alparslan & $763.8 \mathrm{c}-\mathrm{q}$ & $747.5 \mathrm{a}-\mathrm{g}$ & 755.6 a-1 & 17.9 a-e & $29.1 \mathrm{a}-\mathrm{m}$ & $23.5 \mathrm{a}-1$ \\
\hline 3 & Altay 2000 & $672.5 \mathrm{j}-\mathrm{s}$ & $668.8 \mathrm{a}-\mathrm{h}$ & $670.6 \mathrm{~d}-\mathrm{p}$ & $18.0 \mathrm{a}-\mathrm{d}$ & $35.1 \mathrm{ab}$ & $26.5 \mathrm{a}$ \\
\hline 4 & Atl1 2002 & $942.5 \mathrm{ab}$ & $708.8 \mathrm{a}-\mathrm{g}$ & $825.6 \mathrm{abc}$ & $15.3 \mathrm{~b}-\mathrm{p}$ & $28.5 \mathrm{a}-\mathrm{m}$ & $21.9 \mathrm{~b}-\mathrm{m}$ \\
\hline 5 & Aytın 98 & $952.5 \mathrm{a}$ & 798.8 a-e & $875.6 \mathrm{a}$ & $18.3 \mathrm{a}-\mathrm{d}$ & $31.2 \mathrm{a}-\mathrm{k}$ & $24.7 \mathrm{a}-\mathrm{f}$ \\
\hline 6 & Bağc1 2002 & $825.0 \mathrm{a}-\mathrm{j}$ & $743.8 \mathrm{a}-\mathrm{g}$ & $784.4 \mathrm{a}-\mathrm{h}$ & $18.5 \mathrm{a}-\mathrm{d}$ & $32.9 \mathrm{a}-\mathrm{g}$ & $25.7 \mathrm{abc}$ \\
\hline 7 & Bayraktar 2000 & $771.3 \mathrm{c}-\mathrm{O}$ & 825.0 a-e & $798.1 \mathrm{a}-\mathrm{f}$ & $16.5 \mathrm{a}-\mathrm{k}$ & $23.1 \mathrm{i}-\mathrm{s}$ & $19.8 \mathrm{i}-\mathrm{p}$ \\
\hline 8 & Bolal 2973 & $831.3 \mathrm{a}-\mathrm{i}$ & $741.3 \mathrm{a}-\mathrm{g}$ & $786.3 \mathrm{a}-\mathrm{g}$ & $18.5 \mathrm{a}-\mathrm{d}$ & 30.4 a-1 & $24.4 \mathrm{a}-\mathrm{h}$ \\
\hline 9 & Çetinel 2000 & $832.5 \mathrm{a}-\mathrm{i}$ & $742.5 \mathrm{a}-\mathrm{g}$ & $787.5 \mathrm{a}-\mathrm{g}$ & $17.0 \mathrm{a}-\mathrm{h}$ & $32.5 \mathrm{a}-\mathrm{g}$ & $24.8 \mathrm{a}-\mathrm{f}$ \\
\hline 10 & Dağdaş 94 & $638.8 \mathrm{~m}-\mathrm{s}$ & $712.5 \mathrm{a}-\mathrm{g}$ & $675.6 \mathrm{~d}-\mathrm{p}$ & $18.8 \mathrm{ab}$ & $29.0 \mathrm{a}-\mathrm{m}$ & 23.9 a-j \\
\hline 11 & Demir 2000 & $648.81-\mathrm{s}$ & $742.5 \mathrm{a}-\mathrm{g}$ & $695.6 c-p$ & $18.1 \mathrm{a}-\mathrm{d}$ & $32.6 \mathrm{a}-\mathrm{g}$ & $25.4 \mathrm{a}-\mathrm{d}$ \\
\hline 12 & Doğankent 1 & $755.0 \mathrm{~d}-\mathrm{q}$ & $446.3 \mathrm{hij}$ & $600.6 n-q$ & $17.5 \mathrm{a}-\mathrm{f}$ & $31.7 \mathrm{a}-\mathrm{h}$ & $24.6 \mathrm{a}-\mathrm{g}$ \\
\hline 13 & Doğu 88 & $913.8 \mathrm{abc}$ & 828.8 a-e & $871.3 \mathrm{ab}$ & $16.5 \mathrm{a}-\mathrm{k}$ & $25.0 \mathrm{f}-\mathrm{r}$ & $20.8 \mathrm{~d}-\mathrm{o}$ \\
\hline 14 & Gerek 79 & $766.3 \mathrm{c}-\mathrm{p}$ & $777.5 \mathrm{a}-\mathrm{f}$ & $771.9 \mathrm{a}-\mathrm{j}$ & $14.9 \mathrm{~d}-\mathrm{q}$ & $23.5 \mathrm{~h}-\mathrm{s}$ & $19.2 \mathrm{k}-\mathrm{p}$ \\
\hline 15 & Gün 91 & $680.0 \mathrm{i}-\mathrm{s}$ & $852.5 \mathrm{a}-\mathrm{d}$ & $766.3 \mathrm{a}-\mathrm{j}$ & $15.0 \mathrm{~b}-\mathrm{q}$ & 33.9 a-e & $24.4 \mathrm{a}-\mathrm{h}$ \\
\hline 16 & Harmankaya 99 & $911.3 \mathrm{abc}$ & $762.5 \mathrm{a}-\mathrm{g}$ & $836.9 \mathrm{abc}$ & $11.4 \mathrm{qr}$ & $34.6 \mathrm{abc}$ & 23.0 a-1 \\
\hline 17 & İkizce 96 & $763.8 \mathrm{c}-\mathrm{q}$ & $775.0 \mathrm{a}-\mathrm{f}$ & $769.4 \mathrm{a}-\mathrm{j}$ & $12.2 \mathrm{n}-\mathrm{r}$ & $21.5 \mathrm{~m}-\mathrm{t}$ & 16.8 n-r \\
\hline 18 & İzgi 2001 & $786.3 \mathrm{c}-\mathrm{n}$ & $748.8 \mathrm{a}-\mathrm{g}$ & $767.5 \mathrm{a}-\mathrm{j}$ & $16.3 \mathrm{a}-1$ & $35.2 \mathrm{ab}$ & $25.7 \mathrm{abc}$ \\
\hline 19 & Karahan 99 & $690.0 \mathrm{~h}-\mathrm{s}$ & $805.0 \mathrm{a}-\mathrm{e}$ & 747.5 a-n & $17.4 \mathrm{a}-\mathrm{g}$ & $32.7 \mathrm{a}-\mathrm{g}$ & 25.0 a-e \\
\hline 20 & Kate A-1 & $695.0 \mathrm{~h}-\mathrm{s}$ & $721.3 \mathrm{a}-\mathrm{g}$ & $708.1 \mathrm{c}-\mathrm{o}$ & $13.1 \mathrm{i}-\mathrm{r}$ & 28.0 a-o & $20.6 \mathrm{e}-\mathrm{o}$ \\
\hline 21 & Kuraç 66 & $881.3 \mathrm{a}-\mathrm{f}$ & 808.8 a-e & $845.0 \mathrm{abc}$ & 17.7 a-e & $28.2 \mathrm{a}-\mathrm{n}$ & 23.0 a-1 \\
\hline 22 & Kırg1z 95 & $790.0 \mathrm{c}-\mathrm{m}$ & $715.0 \mathrm{a}-\mathrm{g}$ & $752.5 \mathrm{a}-\mathrm{m}$ & $12.2 \mathrm{n}-\mathrm{r}$ & $33.4 \mathrm{a}-\mathrm{f}$ & 22.8 a-1 \\
\hline 23 & Kırkpınar 79 & $627.5 \mathrm{o}-\mathrm{s}$ & $537.5 \mathrm{f}-\mathrm{i}$ & $582.5 \mathrm{opq}$ & $17.0 \mathrm{a}-\mathrm{h}$ & $31.8 \mathrm{a}-\mathrm{h}$ & $24.4 \mathrm{a}-\mathrm{i}$ \\
\hline 24 & Kutluk 94 & $788.8 \mathrm{c}-\mathrm{m}$ & $865.0 \mathrm{abc}$ & 826.9 abc & $16.6 \mathrm{a}-\mathrm{j}$ & 27.3 a-o & $21.9 \mathrm{~b}-\mathrm{m}$ \\
\hline 25 & Lancer & 898.8 a-d & $701.3 \mathrm{a}-\mathrm{g}$ & 800.0 a-f & $18.4 \mathrm{a}-\mathrm{d}$ & $23.7 \mathrm{~h}-\mathrm{s}$ & $21.1 \mathrm{~d}-\mathrm{o}$ \\
\hline 26 & Mizrak & $613.8 \mathrm{p}-\mathrm{s}$ & $681.3 \mathrm{a}-\mathrm{h}$ & 647.5 g-p & $16.7 \mathrm{a}-\mathrm{i}$ & 24.7 g-r & 20.7 e-o \\
\hline 27 & Müfitbey & $693.8 \mathrm{~h}-\mathrm{s}$ & $896.3 \mathrm{ab}$ & $795.0 \mathrm{a}-\mathrm{g}$ & $12.0 \mathrm{o}-\mathrm{r}$ & $31.4 \mathrm{a}-\mathrm{j}$ & $21.7 \mathrm{~b}-\mathrm{m}$ \\
\hline 28 & Nenehatun & 607.5 qrs & $735.0 \mathrm{a}-\mathrm{g}$ & $671.3 \mathrm{~d}-\mathrm{p}$ & $18.1 \mathrm{a}-\mathrm{d}$ & $31.0 \mathrm{a}-1$ & $24.5 \mathrm{a}-\mathrm{g}$ \\
\hline 29 & Palandöken 97 & $658.81-\mathrm{s}$ & $748.8 \mathrm{a}-\mathrm{g}$ & 703.8 c-p & $13.8 \mathrm{~g}-\mathrm{q}$ & $34.9 \mathrm{ab}$ & $24.3 \mathrm{a}-\mathrm{i}$ \\
\hline 30 & Pamukova 97 & $712.5 \mathrm{~g}-\mathrm{r}$ & $278.8 \mathrm{j}$ & $495.6 \mathrm{q}$ & $17.7 \mathrm{a}-\mathrm{f}$ & $34.1 \mathrm{a}-\mathrm{d}$ & $25.9 \mathrm{ab}$ \\
\hline 31 & Pehlivan & $612.5 \mathrm{p}-\mathrm{s}$ & $658.8 \mathrm{a}-\mathrm{h}$ & 635.6 h-p & $9.7 \mathrm{r}$ & $29.5 \mathrm{a}-\mathrm{m}$ & 19.6 j-p \\
\hline 32 & Prostor & $660.01-\mathrm{s}$ & $682.5 \mathrm{a}-\mathrm{h}$ & $671.3 \mathrm{~d}-\mathrm{p}$ & $11.7 \mathrm{pqr}$ & $30.4 \mathrm{a}-1$ & $21.1 \mathrm{~d}-\mathrm{o}$ \\
\hline 33 & Seri 82 & 797.5 b-1 & $321.3 \mathrm{ij}$ & $559.4 \mathrm{pq}$ & $12.61-\mathrm{r}$ & $30.4 \mathrm{a}-1$ & $21.5 \mathrm{~b}-\mathrm{m}$ \\
\hline 34 & Soyer 02 & $732.5 \mathrm{f}-\mathrm{q}$ & 802.5 a-e & $767.5 \mathrm{a}-\mathrm{j}$ & $12.8 \mathrm{k}-\mathrm{r}$ & $34.5 \mathrm{abc}$ & 23.6 a-1 \\
\hline 35 & Sönmez 2001 & $743.8 \mathrm{e}-\mathrm{q}$ & $695.0 \mathrm{a}-\mathrm{g}$ & 719.4 c-o & $16.5 \mathrm{a}-\mathrm{k}$ & $31.6 \mathrm{a}-\mathrm{i}$ & $24.0 \mathrm{a}-\mathrm{j}$ \\
\hline 36 & Sultan 95 & $735.0 \mathrm{e}-\mathrm{q}$ & $780.0 \mathrm{a}-\mathrm{f}$ & 757.5 a-1 & $13.2 \mathrm{i}-\mathrm{r}$ & $29.6 \mathrm{a}-\mathrm{m}$ & 21.4 b-n \\
\hline 37 & Süzen 97 & $652.51-\mathrm{s}$ & $832.5 \mathrm{a}-\mathrm{e}$ & 742.5 a-n & 17.7 a-e & $35.4 \mathrm{a}$ & $26.6 \mathrm{a}$ \\
\hline 38 & Tosunbey & $666.31-s$ & $672.5 \mathrm{a}-\mathrm{h}$ & $669.4 \mathrm{~d}-\mathrm{p}$ & $12.61-\mathrm{r}$ & 30.9 a-1 & $21.7 \mathrm{~b}-\mathrm{m}$ \\
\hline 39 & Türkmen & $781.3 \mathrm{c}-\mathrm{o}$ & 802.5 a-e & $791.9 \mathrm{a}-\mathrm{g}$ & $15.8 \mathrm{~b}-\mathrm{n}$ & 25.7 d-r & $20.8 \mathrm{~d}-\mathrm{o}$ \\
\hline 40 & Uzunyayla & $742.5 \mathrm{e}-\mathrm{q}$ & 846.3 a-e & $794.4 \mathrm{a}-\mathrm{g}$ & $18.7 \mathrm{abc}$ & $32.9 \mathrm{a}-\mathrm{g}$ & $25.8 \mathrm{abc}$ \\
\hline 41 & Yakar 99 & $718.8 \mathrm{~g}-\mathrm{r}$ & $755.0 \mathrm{a}-\mathrm{g}$ & 736.9 a-n & $13.0 \mathrm{j}-\mathrm{r}$ & $26.3 c-q$ & 19.6 j-p \\
\hline 42 & Zencirci 2002 & $780.0 \mathrm{c}-\mathrm{O}$ & 833.8 a-e & 806.9 a-e & $13.6 \mathrm{~h}-\mathrm{q}$ & $26.1 \mathrm{c}-\mathrm{q}$ & 19.9 h-p \\
\hline
\end{tabular}


Çizelge 3. Buğday genotiplerinin 2009-10 ve 2010-11 ürün yılları ile ürün yıllarının ortalaması olarak m2'deki başak ve başaktaki tane sayıları (devam)

\begin{tabular}{|c|c|c|c|c|c|c|c|}
\hline 43 & Ak-702 & $667.5 \mathrm{k}-\mathrm{s}$ & $665.0 \mathrm{a}-\mathrm{h}$ & $666.3 \mathrm{e}-\mathrm{p}$ & $14.9 \mathrm{c}-\mathrm{q}$ & $25.2 \mathrm{f}-\mathrm{r}$ & $20.1 \mathrm{~g}-\mathrm{p}$ \\
\hline 44 & Ak Buğday & $836.3 \mathrm{a}-\mathrm{h}$ & $736.3 \mathrm{a}-\mathrm{g}$ & $786.3 \mathrm{a}-\mathrm{g}$ & $17.2 \mathrm{a}-\mathrm{h}$ & $17.4 \mathrm{rst}$ & $17.3 \mathrm{~m}-\mathrm{r}$ \\
\hline 45 & Ankara 093/44 & $655.01-\mathrm{s}$ & $792.5 \mathrm{a}-\mathrm{f}$ & $723.8 \mathrm{~b}-\mathrm{o}$ & $14.0 \mathrm{f}-\mathrm{q}$ & $27.4 \mathrm{a}-\mathrm{o}$ & 20.7 e-o \\
\hline 46 & Conkesme & 705.0 g-r & $628.8 \mathrm{c}-\mathrm{h}$ & 666.9 e-p & $16.2 \mathrm{a}-\mathrm{m}$ & $19.9 \mathrm{n}-\mathrm{t}$ & $18.0 \mathrm{~m}-\mathrm{q}$ \\
\hline 47 & Haymana 79 & $830.0 \mathrm{a}-\mathrm{i}$ & $693.8 \mathrm{a}-\mathrm{g}$ & $761.9 \mathrm{a}-\mathrm{k}$ & $19.8 \mathrm{a}$ & 27.8 a-o & $23.8 \mathrm{a}-\mathrm{k}$ \\
\hline 48 & Hawk (Şahin) & $886.3 \mathrm{a}-\mathrm{e}$ & $767.5 \mathrm{a}-\mathrm{g}$ & $826.9 \mathrm{abc}$ & $14.1 \mathrm{e}-\mathrm{q}$ & $28.6 \mathrm{a}-\mathrm{m}$ & $21.4 \mathrm{~b}-\mathrm{n}$ \\
\hline 49 & Kılçıksız Buğday & $691.3 \mathrm{~h}-\mathrm{s}$ & $655.0 \mathrm{a}-\mathrm{h}$ & $673.1 \mathrm{~d}-\mathrm{p}$ & $13.0 \mathrm{j}-\mathrm{r}$ & $15.9 \mathrm{st}$ & $14.4 \mathrm{qr}$ \\
\hline 50 & Kirik & $550.0 \mathrm{~s}$ & $660.0 \mathrm{a}-\mathrm{h}$ & $605.0 \mathrm{~m}-\mathrm{q}$ & $13.0 \mathrm{i}-\mathrm{r}$ & $14.4 \mathrm{t}$ & $13.7 \mathrm{r}$ \\
\hline 51 & Kırmızı Kılçık & $763.8 \mathrm{c}-\mathrm{q}$ & $785.0 \mathrm{a}-\mathrm{f}$ & $774.4 \mathrm{a}-\mathrm{i}$ & $12.3 \mathrm{n}-\mathrm{r}$ & 27.0 a-o & $19.6 \mathrm{j}-\mathrm{p}$ \\
\hline 52 & Kırmızı Yerli & $855.0 \mathrm{a}-\mathrm{g}$ & $593.8 \mathrm{~d}-\mathrm{h}$ & $724.4 \mathrm{~b}-\mathrm{o}$ & $12.0 \mathrm{o}-\mathrm{r}$ & $19.7 \mathrm{o}-\mathrm{t}$ & $15.8 \mathrm{pqr}$ \\
\hline 53 & Koca Buğday & $695.0 \mathrm{~h}-\mathrm{s}$ & $903.8 \mathrm{a}$ & $799.4 \mathrm{a}-\mathrm{f}$ & $15.0 \mathrm{c}-\mathrm{q}$ & $18.6 \mathrm{p}-\mathrm{t}$ & $16.8 \mathrm{o}-\mathrm{r}$ \\
\hline 54 & Köse 220/39 & $731.3 \mathrm{f}-\mathrm{q}$ & $790.0 \mathrm{a}-\mathrm{f}$ & $760.6 \mathrm{a}-\mathrm{k}$ & $12.61-\mathrm{r}$ & $21.1 \mathrm{~m}-\mathrm{t}$ & 16.9 n-r \\
\hline 55 & Orso & 705.0 g-r & $515.0 \mathrm{ghi}$ & $610.01-q$ & $16.1 \mathrm{~b}-\mathrm{m}$ & $25.0 \mathrm{f}-\mathrm{r}$ & 20.5 e-o \\
\hline 56 & Özlü Buğday & $740.0 \mathrm{e}-\mathrm{q}$ & 797.5 a-e & $768.8 \mathrm{a}-\mathrm{j}$ & $18.3 \mathrm{a}-\mathrm{d}$ & 25.4 e-r & $21.9 \mathrm{~b}-\mathrm{m}$ \\
\hline 57 & Polatlı Kösesi & $963.8 \mathrm{a}$ & $673.8 \mathrm{a}-\mathrm{h}$ & $818.8 \mathrm{a}-\mathrm{d}$ & $17.7 \mathrm{a}-\mathrm{f}$ & $22.51-\mathrm{s}$ & $20.1 \mathrm{~g}-\mathrm{p}$ \\
\hline 58 & Sert Buğday & $671.3 \mathrm{j}-\mathrm{s}$ & $821.3 \mathrm{a}-\mathrm{e}$ & 746.3 a-n & $13.0 \mathrm{i}-\mathrm{r}$ & $25.1 \mathrm{f}-\mathrm{r}$ & $19.11-\mathrm{p}$ \\
\hline 59 & Sürak 1593/51 & $657.5 \mathrm{l}-\mathrm{s}$ & $591.3 \mathrm{e}-\mathrm{h}$ & $624.4 j-q$ & $12.5 \mathrm{~m}-\mathrm{r}$ & $22.71-\mathrm{s}$ & $17.6 \mathrm{~m}-\mathrm{r}$ \\
\hline 60 & Tir & $630.0 \mathrm{n}-\mathrm{s}$ & $603.8 \mathrm{~d}-\mathrm{h}$ & $616.9 \mathrm{k}-\mathrm{q}$ & $16.7 \mathrm{a}-\mathrm{j}$ & $23.0 \mathrm{j}-\mathrm{s}$ & 19.8 h-p \\
\hline 61 & Yayla 305 & $571.0 \mathrm{rs}$ & $680.0 \mathrm{a}-\mathrm{h}$ & $627.5 \mathrm{i}-\mathrm{q}$ & $17.1 \mathrm{a}-\mathrm{h}$ & $22.8 \mathrm{k}-\mathrm{s}$ & $20.0 \mathrm{~g}-\mathrm{p}$ \\
\hline 62 & Zerin & $672.5 \mathrm{j}-\mathrm{s}$ & $636.3 \mathrm{~b}-\mathrm{h}$ & $654.4 \mathrm{f}-\mathrm{p}$ & $15.7 \mathrm{~b}-\mathrm{o}$ & $18.2 \mathrm{r}-\mathrm{t}$ & $16.9 \mathrm{n}-\mathrm{r}$ \\
\hline 63 & Bezostaja 1 & $700.0 \mathrm{~h}-\mathrm{s}$ & $725.0 \mathrm{a}-\mathrm{g}$ & $712.5 \mathrm{c}-\mathrm{O}$ & $15.9 \mathrm{~b}-\mathrm{n}$ & $26.7 b-p$ & $21.3 \mathrm{c}-\mathrm{o}$ \\
\hline 64 & Karasu 90 & $822.5 \mathrm{a}-\mathrm{k}$ & $717.5 \mathrm{a}-\mathrm{g}$ & $770.0 \mathrm{a}-\mathrm{j}$ & $18.4 \mathrm{a}-\mathrm{d}$ & $23.6 \mathrm{~h}-\mathrm{s}$ & $21.0 \mathrm{~d}-\mathrm{o}$ \\
\hline \multicolumn{2}{|c|}{ Ortalama } & $741.5 \mathrm{~A}$ & $719.0 \mathrm{~B}$ & 730.2 & $15.5 \mathrm{~A}$ & $27.4 \mathrm{~B}$ & 21.5 \\
\hline \multicolumn{2}{|c|}{ F değeri (Genotip) } & $7.96 * *$ & $4.35 * *$ & $6.03 * *$ & $8.81 * *$ & $7.91 * *$ & $8.85^{* *}$ \\
\hline \multicolumn{2}{|c|}{ F değeri (Y1l) } & - & - & $7.64 * *$ & - & - & $2213.91 * *$ \\
\hline \multicolumn{2}{|c|}{$F$ değeri (GxY) } & - & - & $4.63 * *$ & - & - & $7.26^{* *}$ \\
\hline \multicolumn{2}{|c|}{$\mathrm{AÖF}(0.01)(\mathrm{G})$} & 124.8 & 205.0 & 119.4 & 3.0 & 6.8 & 3.7 \\
\hline \multicolumn{2}{|c|}{$\mathrm{AÖF}(0.01)(\mathrm{Y})$} & - & - & 21.1 & - & - & 0.7 \\
\hline \multicolumn{2}{|c|}{ AÖF (0.01) (GxY) } & - & - & 168.9 & - & - & 5.3 \\
\hline \multicolumn{2}{|c|}{ Varyasyon Katsayısı (\%) } & 9.2 & 15.5 & 12.6 & 10.6 & 13.5 & 13.4 \\
\hline
\end{tabular}

Aynı harfle gösterilen ortalamalar birbirinden farksızdır. ** İstatistiksel olarak \%1 düzeyinde önemlidir

Başaktaki tane sayısı yönünden buğday genotipleri arasındaki farkların iki ürün yılında ve ürün yılları ortalamasında önemli olduğu tespit edilmiştir. Başaktaki tane sayısına yılların etkisi de önemli olmuş, genotiplerin ortalaması olarak 2009-10 ürün yılında (15.5), 2010-11 ürün yılına (27.4) göre önemli derecede düşük başakta tane sayısı belirlenmiştir. Buğdayda generatif organlar düşük sıcaklık derecelerine hassastır ve çiçekler $0^{\circ} \mathrm{C}$ 'nin altında zarar görmektedir. Genotiplerin gebecik-başaklanma döneminde oldukları 25 Mayıs 2010 tarihinde sıcaklığın $-0.4^{\circ} C^{\prime}$ ye düşmesi, bütün çeşitlerde çiçek ölümlerine neden olarak birinci ürün yılında başaktaki tane sayısını azaltmıştır. Genotiplerin, başaktaki tane sayısı yönünden sıralanışı yıllara göre de farklılık göstermiş ve "genotip x yıl” interaksiyonu önemli olmuştur (Çizelge 3).

Buğday genotiplerinin başaktaki tane sayıları 2009-10 ürün yılında 9.7 ile 19.8, 2010-11 ürün yılında ise 14.4 ile 35.4 arasında değişim göstermiştir. Başaktaki tane sayısı 2009-10 ürün yılında en fazla Haymana 79, Dağdaş 94 ve Uzunyayla çeşitlerinde ve sırasıyla 19.8, 18.8 ve 18.7 adet; 2010-11 ürün yılında ise Süzen 97, İzgi 2001 ve Altay 2000 çeşitlerinde ve sırasıyla 35.4, 35.2 ve 35.1 adet olarak tespit edilmiştir. En düşük başaktaki tane sayıları 2009-10 ürün yılında Pehlivan (9.7), Harmankaya 99 (11.4) ve Prostor (11.7); 2010-11 ürün yılında ise Kırik (14.4), Kılçıksız Buğday (15.9) ve Ak Buğday (17.4) genotiplerinde belirlenmiştir. Başaktaki fertil başakçık ve fertil çiçek sayısının genotiplere göre değişmesi, başaktaki tane sayısı farklılığının kaynağını oluşturmaktadır. İlkbahar geç don olayının yaşandığı birinci ürün yılında, başaktaki tane sayılarındaki azalma oranları, çeşitlerin don tarihindeki fenolojik gelişme dönemleri ile de ilişkilidir. Bu ürün yılında, başaktaki tane sayısı yönünden yerel çeşitler ile ıslah çeşitleri yakınlık göstermiş, ikinci ürün yılında 1slah çeşitlerinin üstünlüğü dikkat çekmiştir. Ürün yıllarının ortalaması olarak genotiplerin başaktaki tane sayıları 13.7-26.6 arasında olmuştur. Başaktaki tane sayısı en yüksek çeşit Süzen 97 olmuş, bu çeşidi azalan sıra ile Altay 2000 (26.5), Pamukova 97 (25.9), Uzunyayla (25.8) ve İzgi 2001 (25.7) çeşitleri takip etmiştir. Başaktaki tane sayıları en düşük genotipler ise Kırik (13.7), Kılçıksız Buğday (14.4) ve Kırmızı Yerli (15.8) olmuştur (Çizelge 3). Bulgularımızdan yüksek olarak Çağlar ve ark. (2006), Erzurum koşullarında 25 ekmeklik buğday çeşidi ile yürüttükleri araştırmada başaktaki tane sayısının 19.9-30.4 adet, Özen ve Akman (2015) ise Yozgat kuru tarım koşullarında 14 ekmeklik buğday çeşidinde başaktaki tane sayısının 22-46 adet arasında değişim gösterdiğini 
tespit etmişlerdir.

Bin tane ağırlığı yönünden buğday genotipleri arasındaki farklar önemli bulunmuştur. Bin tane ağırlığ üzerine ürün yıllarının etkisi de önemli olmuş, 2009-10 ürün yllında (32.9 g), 2010-11 ürün yılına (39.9 g) göre daha düşük tane ağırlığı belirlenmiştir. Genotiplerin 1000 tane ağırlığı yönünden sıralanışı yıllara göre farklılık göstermiş ve "genotip x yll" interaksiyonu önemli çıkmıştır (Çizelge 4).

Genotiplerin 1000 tane ağırlıkları 2009-2010 ürün yılında 22.1 ile $43.0 \mathrm{~g}, 2010-11$ ürün yılında 31.6 ile $45.2 \mathrm{~g}$, ürün yılları ortalaması olarak ise 28.9 ile $43.3 \mathrm{~g}$ arasında değişim göstermiş, ortalama değer ise $36.4 \mathrm{~g}$ olarak tespit edilmiştir. Buğdayın tane ağırlı̆̆ esas olarak çiçeklenme sonrası gelişme süreçleri ve çevre koşulları tarafından belirlenir (Wiegand ve ark. 1981). Çiçeklenme sonrası dönemdeki serin ve nemli hava koşulları, 2009-10 ürün yılında şiddetli sarı pas enfeksiyonuna neden olarak genotiplerin çoğunda 1000 tane ağırlığını önemli oranda azaltımıştır. Bu ürün yılında Sönmez 2001 çeşidi en yüksek 1000 tane ağırlığına ( 43.0 g) sahip olmuş, bu çeşidi 42.6 g, 41.3 g ve 40.5 g 1000 tane ağırlıkları ile sırasıyla Tir, Sürak 1593/51 ve Dağdaş 94 genotipleri izlemiştir.

Çizelge 4. Buğday genotiplerinin 2009-10 ve 2010-11 ürün yılları ile ürün yıllarının ortalaması olarak bin tane ağırlıkları ve tane verimleri

\begin{tabular}{|c|c|c|c|c|c|c|c|}
\hline \multirow{2}{*}{ No } & \multirow{2}{*}{ Genotip } & \multicolumn{3}{|c|}{ Bin tane ağırlığı $(g)$} & \multicolumn{2}{|c|}{ Tane verimi $(\mathrm{kg} / \mathrm{da})$} & \multirow[b]{2}{*}{ Ortalama } \\
\hline & & 2009-10 & 2010-11 & Ortalama & 2009-10 & 2010-11 & \\
\hline 1 & Aksel 2000 & 34.7 e-n & 40.9 a-e & $37.8 \mathrm{c}-\mathrm{n}$ & $416.0 \mathrm{~h}-\mathrm{n}$ & $616.9 \mathrm{o}-\mathrm{u}$ & $516.41-u$ \\
\hline 2 & Alparslan & $24.2 \mathrm{z}$ & 33.5 cde & $28.9 \mathrm{r}$ & 316.9 p-y & $662.4 \mathrm{~m}-\mathrm{t}$ & $489.7 \mathrm{n}-\mathrm{v}$ \\
\hline 3 & Altay 2000 & $31.9 \mathrm{i}-\mathrm{w}$ & $41.8 \mathrm{a}-\mathrm{d}$ & $36.8 \mathrm{~d}-\mathrm{p}$ & $366.11-\mathrm{s}$ & $717.1 \mathrm{j}-\mathrm{r}$ & $541.6 \mathrm{i}-\mathrm{r}$ \\
\hline 4 & Atlı 2002 & $35.4 \mathrm{e}-1$ & $42.9 \mathrm{abc}$ & $39.1 \mathrm{a}-\mathrm{i}$ & $650.1 \mathrm{a}$ & $862.4 \mathrm{c}-\mathrm{k}$ & $756.3 \mathrm{a}$ \\
\hline 5 & Aytın 98 & $29.0 \mathrm{t}-\mathrm{z}$ & $40.1 \mathrm{a}-\mathrm{e}$ & $34.6 \mathrm{~g}-\mathrm{q}$ & $483.2 \mathrm{~d}-\mathrm{g}$ & $788.1 \mathrm{~h}-\mathrm{o}$ & $635.7 \mathrm{~b}-\mathrm{h}$ \\
\hline 6 & Bağc1 2002 & $37.2 \mathrm{c}-\mathrm{g}$ & 36.8 a-e & $37.0 \mathrm{~d}-\mathrm{p}$ & $542.1 \mathrm{bcd}$ & 826.9 e-m & $684.5 \mathrm{a}-\mathrm{d}$ \\
\hline 7 & Bayraktar 2000 & $36.6 \mathrm{~d}-\mathrm{i}$ & 39.7 a-e & $38.1 \mathrm{a}-\mathrm{m}$ & $441.0 \mathrm{~g}-\mathrm{k}$ & $907.1 \mathrm{~b}-\mathrm{h}$ & $674.1 \mathrm{a}-\mathrm{e}$ \\
\hline 8 & Bolal 2973 & $28.4 \mathrm{v}-\mathrm{z}$ & 39.1 a-e & 33.8 h-r & $424.5 \mathrm{~g}-1$ & $831.2 \mathrm{~d}-\mathrm{m}$ & $627.8 \mathrm{~b}-\mathrm{i}$ \\
\hline 9 & Çetinel 2000 & $33.5 \mathrm{~g}-\mathrm{u}$ & 40.3 a-e & $36.9 \mathrm{~d}-\mathrm{p}$ & $447.3 \mathrm{~g}-\mathrm{j}$ & 770.9 h-p & $609.1 \mathrm{c}-\mathrm{k}$ \\
\hline 10 & Dağdaş 94 & $40.5 \mathrm{a}-\mathrm{d}$ & 40.3 a-e & $40.4 \mathrm{a}-\mathrm{f}$ & $472.4 \mathrm{e}-\mathrm{h}$ & 798.6 g-n & $635.5 \mathrm{~b}-\mathrm{h}$ \\
\hline 11 & Demir 2000 & $31.21-\mathrm{x}$ & 40.9 a-e & $36.1 \mathrm{~d}-\mathrm{p}$ & $376.8 \mathrm{k}-\mathrm{r}$ & $1136.7 \mathrm{a}$ & $756.8 \mathrm{a}$ \\
\hline 12 & Doğankent 1 & $28.5 \mathrm{v}-\mathrm{z}$ & $31.6 \mathrm{e}$ & $30.0 \mathrm{qr}$ & $347.3 \mathrm{o}-\mathrm{v}$ & 299.7 z & $323.5 \mathrm{z}$ \\
\hline 13 & Doğu 88 & $35.3 \mathrm{e}-1$ & 37.5 a-e & $36.4 \mathrm{~d}-\mathrm{p}$ & $520.5 \mathrm{c}-\mathrm{f}$ & $897.0 \mathrm{~b}-\mathrm{i}$ & $708.8 \mathrm{ab}$ \\
\hline 14 & Gerek 79 & $30.1 \mathrm{n}-\mathrm{y}$ & 37.0 a-e & $33.6 \mathrm{j}-\mathrm{r}$ & $430.9 \mathrm{~g}-1$ & $679.11-\mathrm{t}$ & $555.0 \mathrm{~g}-\mathrm{q}$ \\
\hline 15 & Gün 91 & $30.3 \mathrm{~m}-\mathrm{y}$ & $34.8 \mathrm{~b}-\mathrm{e}$ & $32.5 \mathrm{n}-\mathrm{r}$ & $299.2 \mathrm{t}-\mathrm{z}$ & $1047.2 \mathrm{ab}$ & $673.2 \mathrm{a}-\mathrm{e}$ \\
\hline 16 & Harmankaya 99 & $34.1 \mathrm{e}-\mathrm{q}$ & 39.5 a-e & $36.8 \mathrm{~d}-\mathrm{p}$ & $354.1 \mathrm{n}-\mathrm{v}$ & 736.1 h-r & 544.6 h-r \\
\hline 17 & İkizce 96 & $27.2 \mathrm{w}-\mathrm{z}$ & 38.9 a-e & $33.11-r$ & $264.0 \mathrm{yz}$ & $669.11-\mathrm{t}$ & $466.6 \mathrm{p}-\mathrm{x}$ \\
\hline 18 & İzgi 2001 & 38.9 a-e & 40.9 a-e & $39.9 \mathrm{a}-\mathrm{g}$ & $520.6 \mathrm{c}-\mathrm{f}$ & $682.11-\mathrm{t}$ & $601.4 \mathrm{~d}-1$ \\
\hline 19 & Karahan 99 & $35.5 \mathrm{e}-1$ & 35.7 a-e & $35.6 \mathrm{~d}-\mathrm{p}$ & $420.2 \mathrm{~g}-\mathrm{m}$ & $1000.0 \mathrm{a}-\mathrm{d}$ & $710.1 \mathrm{ab}$ \\
\hline 20 & Kate A-1 & $36.1 \mathrm{~d}-\mathrm{k}$ & $32.1 \mathrm{de}$ & 34.1 h-r & $314.2 \mathrm{r}-\mathrm{y}$ & $584.7 \mathrm{r}-\mathrm{u}$ & $449.5 \mathrm{~s}-\mathrm{x}$ \\
\hline 21 & Kiraç 66 & $34.0 \mathrm{f}-\mathrm{s}$ & 37.5 a-e & $35.8 \mathrm{~d}-\mathrm{p}$ & $513.8 \mathrm{c}-\mathrm{f}$ & 842.9 d-1 & $678.4 \mathrm{a}-\mathrm{e}$ \\
\hline 22 & Kirgiz 95 & $29.6 \mathrm{o}-\mathrm{z}$ & 37.8 a-e & $33.7 \mathrm{~h}-\mathrm{r}$ & $273.5 \mathrm{xyz}$ & $1019.9 \mathrm{abc}$ & $646.7 \mathrm{~b}-\mathrm{g}$ \\
\hline 23 & Kırkpınar 79 & $36.4 \mathrm{~d}-\mathrm{j}$ & $41.9 \mathrm{a}-\mathrm{d}$ & $39.2 \mathrm{a}-\mathrm{i}$ & $380.9 \mathrm{k}-\mathrm{q}$ & $463.5 \mathrm{u}-\mathrm{z}$ & $422.2 \mathrm{v}-\mathrm{Z}$ \\
\hline 24 & Kutluk 94 & $37.8 \mathrm{c}-\mathrm{g}$ & $43.2 \mathrm{abc}$ & 40.5 a-f & $479.2 \mathrm{e}-\mathrm{h}$ & 773.2 h-p & $626.2 \mathrm{~b}-\mathrm{i}$ \\
\hline 25 & Lancer & $37.3 \mathrm{c}-\mathrm{g}$ & 40.0 a-e & $38.7 \mathrm{a}-\mathrm{k}$ & $591.4 \mathrm{~b}$ & $802.7 \mathrm{f}-\mathrm{n}$ & $697.0 \mathrm{abc}$ \\
\hline 26 & Mizrak & $34.2 \mathrm{e}-\mathrm{p}$ & $36.4 \mathrm{a}-\mathrm{e}$ & $35.3 \mathrm{f}-\mathrm{q}$ & $332.8 \mathrm{p}-\mathrm{x}$ & $526.5 \mathrm{~s}-\mathrm{w}$ & $429.6 \mathrm{u}-\mathrm{z}$ \\
\hline 27 & Müfitbey & $38.3 \mathrm{~b}-\mathrm{g}$ & $42.6 \mathrm{abc}$ & $40.4 \mathrm{a}-\mathrm{f}$ & $341.5 \mathrm{o}-\mathrm{w}$ & 959.6 b-g & $650.6 \mathrm{~b}-\mathrm{f}$ \\
\hline 28 & Nenehatun & $33.6 \mathrm{f}-\mathrm{t}$ & $41.2 \mathrm{a}-\mathrm{e}$ & $37.4 \mathrm{c}-\mathrm{o}$ & $358.9 \mathrm{~m}-\mathrm{t}$ & $756.8 \mathrm{~h}-\mathrm{q}$ & 557.9 g-p \\
\hline 29 & Palandöken 97 & $34.8 \mathrm{e}-\mathrm{n}$ & $41.0 \mathrm{a}-\mathrm{e}$ & 37.9 b-n & $307.8 \mathrm{~s}-\mathrm{z}$ & $887.1 \mathrm{~b}-\mathrm{j}$ & $597.5 \mathrm{~d}-\mathrm{m}$ \\
\hline 30 & Pamukova 97 & $28.8 \mathrm{u}-\mathrm{z}$ & 40.8 a-e & $34.8 \mathrm{~g}-\mathrm{q}$ & $354.6 \mathrm{n}-\mathrm{u}$ & $192.4 \mathrm{z}$ & $273.5 \mathrm{z}$ \\
\hline 31 & Pehlivan & $36.9 \mathrm{c}-\mathrm{h}$ & 39.2 a-e & $38.1 \mathrm{a}-\mathrm{m}$ & $242.4 \mathrm{z}$ & $890.4 \mathrm{~b}-\mathrm{j}$ & $566.4 \mathrm{f}-\mathrm{o}$ \\
\hline 32 & Prostor & 34.4 e-o & $43.7 \mathrm{ab}$ & $39.0 \mathrm{a}-\mathrm{j}$ & $257.8 \mathrm{yz}$ & $785.4 \mathrm{~h}-\mathrm{O}$ & $521.6 \mathrm{k}-\mathrm{t}$ \\
\hline 33 & Seri 82 & $25.0 \mathrm{z}$ & 40.6 a-e & $32.8 \mathrm{~m}-\mathrm{r}$ & $244.5 \mathrm{z}$ & $243.9 \mathrm{z}$ & $244.2 \mathrm{z}$ \\
\hline 34 & Soyer 02 & $29.4 \mathrm{r}-\mathrm{z}$ & 40.7 a-e & $35.0 \mathrm{f}-\mathrm{q}$ & 266.6 xyz & $972.9 \mathrm{~b}-\mathrm{f}$ & 619.7 b-j \\
\hline 35 & Sönmez 2001 & $43.0 \mathrm{a}$ & $43.7 \mathrm{ab}$ & $43.3 \mathrm{a}$ & $552.7 \mathrm{bc}$ & $715.7 \mathrm{j}-\mathrm{r}$ & $634.2 \mathrm{~b}-\mathrm{h}$ \\
\hline 36 & Sultan 95 & $22.1 \mathrm{z}$ & $42.2 \mathrm{abc}$ & 32.1 o-r & $239.8 \mathrm{z}$ & $844.9 \mathrm{~d}-1$ & $542.4 \mathrm{i}-\mathrm{r}$ \\
\hline 37 & Süzen 97 & $33.8 \mathrm{f}-\mathrm{s}$ & $42.0 \mathrm{a}-\mathrm{d}$ & 37.9 b-n & 383.0 j-p & $964.2 \mathrm{~b}-\mathrm{g}$ & $673.6 \mathrm{a}-\mathrm{e}$ \\
\hline 38 & Tosunbey & 34.9 e-m & 40.9 a-e & 37.9 b-n & $288.8 \mathrm{u}-\mathrm{Z}$ & $636.8 n-u$ & $462.8 \mathrm{r}-\mathrm{x}$ \\
\hline
\end{tabular}


Çizelge 4. Buğday genotiplerinin 2009-10 ve 2010-11 ürün yılları ile ürün yıllarının ortalaması olarak bin tane ağırlıkları ve tane verimleri (devam)

\begin{tabular}{|c|c|c|c|c|c|c|c|}
\hline 39 & Türkmen & $35.8 \mathrm{e}-1$ & $41.0 \mathrm{a}-\mathrm{e}$ & $38.4 \mathrm{a}-1$ & $420.2 \mathrm{~g}-\mathrm{m}$ & 982.9 a-e & $701.5 \mathrm{ab}$ \\
\hline 40 & Uzunyayla & $34.5 \mathrm{e}-\mathrm{n}$ & $37.3 \mathrm{a}-\mathrm{e}$ & $35.9 \mathrm{~d}-\mathrm{p}$ & 448.7 ghi & $735.1 \mathrm{~h}-\mathrm{r}$ & $591.9 \mathrm{e}-\mathrm{m}$ \\
\hline 41 & Yakar 99 & $33.8 \mathrm{f}-\mathrm{s}$ & $41.4 \mathrm{a}-\mathrm{e}$ & $37.6 \mathrm{c}-\mathrm{o}$ & $301.8 \mathrm{~s}-\mathrm{z}$ & 724.7 i-r & $513.21-u$ \\
\hline 42 & Zencirci 2002 & 38.4 b-f & $44.0 \mathrm{ab}$ & $41.2 \mathrm{a}-\mathrm{d}$ & $400.4 \mathrm{i}-\mathrm{o}$ & $691.2 \mathrm{k}-\mathrm{s}$ & $545.8 \mathrm{~h}-\mathrm{r}$ \\
\hline 43 & Ak-702 & $29.4 \mathrm{r}-\mathrm{z}$ & 37.9 a-e & 33.7 i-r & $286.5 \mathrm{v}-\mathrm{Z}$ & $409.2 \mathrm{v}-\mathrm{z}$ & $347.9 \mathrm{z}$ \\
\hline 44 & Ak Buğday & $31.7 \mathrm{j}-\mathrm{w}$ & $44.4 \mathrm{ab}$ & $38.0 \mathrm{a}-\mathrm{m}$ & $430.3 \mathrm{~g}-1$ & $580.0 \mathrm{r}-\mathrm{V}$ & $505.1 \mathrm{~m}-\mathrm{V}$ \\
\hline 45 & Ankara 093/44 & $25.9 \mathrm{yz}$ & 40.9 a-e & $33.4 \mathrm{k}-\mathrm{r}$ & $221.4 \mathrm{z}$ & $610.2 \mathrm{p}-\mathrm{u}$ & $415.8 \mathrm{v}-\mathrm{Z}$ \\
\hline 46 & Conkesme & 35.9 e-1 & $44.0 \mathrm{ab}$ & $39.9 \mathrm{a}-\mathrm{g}$ & $383.2 \mathrm{j}-\mathrm{p}$ & $540.1 \mathrm{~s}-\mathrm{w}$ & $461.7 \mathrm{r}-\mathrm{x}$ \\
\hline 47 & Haymana 79 & $30.3 \mathrm{~m}-\mathrm{y}$ & 37.9 a-e & $34.1 \mathrm{~h}-\mathrm{r}$ & $465.1 \mathrm{e}-\mathrm{i}$ & $617.0 \mathrm{o}-\mathrm{u}$ & 541.0 i-r \\
\hline 48 & Hawk (Şahin) & $36.6 \mathrm{~d}-\mathrm{h}$ & $45.2 \mathrm{a}$ & 40.9 a-e & $438.7 \mathrm{~g}-\mathrm{k}$ & $717.3 \mathrm{j}-\mathrm{r}$ & $578.0 \mathrm{f}-\mathrm{n}$ \\
\hline 49 & Kılçıksız Buğday & 26.7 xyz & 39.5 a-e & $33.11-r$ & $218.8 \mathrm{z}$ & $208.2 \mathrm{z}$ & $213.5 \mathrm{z}$ \\
\hline 50 & Kirik & $30.0 \mathrm{n}-\mathrm{y}$ & $41.0 \mathrm{a}-\mathrm{e}$ & $35.5 \mathrm{e}-\mathrm{p}$ & $209.3 \mathrm{z}$ & $333.8 \mathrm{yz}$ & $271.5 \mathrm{z}$ \\
\hline 51 & Kırmızı Kılçık & $31.11-\mathrm{x}$ & 40.9 a-e & $36.0 \mathrm{~d}-\mathrm{p}$ & $267.2 \mathrm{xyz}$ & 795.3 g-n & $531.2 \mathrm{j}-\mathrm{s}$ \\
\hline 52 & Kırmızı Yerli & $29.3 \mathrm{~s}-\mathrm{z}$ & $36.1 \mathrm{a}-\mathrm{e}$ & $32.7 \mathrm{~m}-\mathrm{r}$ & $275.5 \mathrm{w}-\mathrm{Z}$ & $302.3 \mathrm{z}$ & $288.9 \mathrm{z}$ \\
\hline 53 & Koca Buğday & $31.5 \mathrm{k}-\mathrm{w}$ & 38.2 a-e & $34.9 \mathrm{~g}-\mathrm{q}$ & 314.8 r-y & $477.4 \mathrm{u}-\mathrm{y}$ & $396.1 \mathrm{w}-\mathrm{z}$ \\
\hline 54 & Köse 220/39 & $25.0 \mathrm{z}$ & 38.5 a-e & $31.7 \mathrm{pqr}$ & $219.1 \mathrm{z}$ & $488.5 \mathrm{u}-\mathrm{y}$ & 353.8 yz \\
\hline 55 & Orso & $31.6 \mathrm{k}-\mathrm{W}$ & $32.2 \mathrm{de}$ & $31.9 \mathrm{pqr}$ & 340.7 o-w & $411.8 \mathrm{v}-\mathrm{Z}$ & 376.2 xyz \\
\hline 56 & Özlü Buğday & $26.8 \mathrm{xyz}$ & 37.5 a-e & 32.1 o-r & $343.7 \mathrm{o}-\mathrm{v}$ & $489.8 \mathrm{u}-\mathrm{y}$ & $416.7 \mathrm{v}-\mathrm{z}$ \\
\hline 57 & Polatlı Kösesi & $33.8 \mathrm{f}-\mathrm{s}$ & 40.2 a-e & $37.0 \mathrm{~d}-\mathrm{p}$ & $525.1 \mathrm{cde}$ & $511.2 \mathrm{t}-\mathrm{x}$ & $518.1 \mathrm{k}-\mathrm{u}$ \\
\hline 58 & Sert Buğday & $34.1 \mathrm{f}-\mathrm{r}$ & $44.3 \mathrm{ab}$ & $39.2 \mathrm{a}-\mathrm{h}$ & $273.6 \mathrm{xyz}$ & $480.0 \mathrm{u}-\mathrm{y}$ & 376.8 xyz \\
\hline 59 & Sürak 1593/51 & $41.3 \mathrm{abc}$ & $44.0 \mathrm{ab}$ & $42.6 \mathrm{abc}$ & 320.4 p-y & $370.4 \mathrm{w}-\mathrm{z}$ & $345.4 \mathrm{z}$ \\
\hline 60 & Tir & $42.6 \mathrm{ab}$ & $43.8 \mathrm{ab}$ & $43.2 \mathrm{ab}$ & $463.6 \mathrm{e}-\mathrm{i}$ & $409.4 \mathrm{v}-\mathrm{z}$ & $436.5 \mathrm{t}-\mathrm{z}$ \\
\hline 61 & Yayla 305 & $29.5 \mathrm{p}-\mathrm{z}$ & $42.3 \mathrm{abc}$ & 35.9 d-p & $297.3 \mathrm{t}-\mathrm{z}$ & $587.9 \mathrm{r}-\mathrm{u}$ & $442.6 \mathrm{~s}-\mathrm{y}$ \\
\hline 62 & Zerin & $30.2 \mathrm{~m}-\mathrm{y}$ & 39.4 a-e & $34.8 \mathrm{~g}-\mathrm{q}$ & $293.1 \mathrm{t}-\mathrm{z}$ & 350.7 xyz & $321.9 \mathrm{z}$ \\
\hline 63 & Bezostaja 1 & $34.2 \mathrm{e}-\mathrm{p}$ & 40.9 a-e & $37.6 \mathrm{c}-\mathrm{O}$ & $375.8 \mathrm{k}-\mathrm{r}$ & $577.1 \mathrm{r}-\mathrm{v}$ & 476.4 o-w \\
\hline 64 & Karasu 90 & $32.3 \mathrm{~h}-\mathrm{v}$ & 39.6 a-e & $35.9 \mathrm{~d}-\mathrm{p}$ & $460.0 \mathrm{f}-\mathrm{i}$ & $529.5 \mathrm{~s}-\mathrm{w}$ & $494.8 \mathrm{n}-\mathrm{v}$ \\
\hline \multicolumn{2}{|c|}{ Ortalama } & $32.9 \mathrm{~A}$ & $39.9 \mathrm{~B}$ & 36.4 & $372.0 \mathrm{~A}$ & $667.5 \mathrm{~B}$ & 519.8 \\
\hline \multicolumn{2}{|c|}{ F değeri (Genotip) } & $17.75 * *$ & $2.04 * *$ & $6.81 * *$ & $45.19 * *$ & $32.03 * *$ & $41.03 * *$ \\
\hline \multicolumn{2}{|c|}{$\mathrm{F}$ değeri (Y1l) } & - & - & $544.91 * *$ & - & - & $3135.52 * *$ \\
\hline \multicolumn{2}{|c|}{ F değeri (GxY) } & - & - & $3.45 * *$ & - & - & $26.41 * *$ \\
\hline \multicolumn{2}{|c|}{ AÖF (0.01) (G) } & 3.9 & 7.9 & 4.4 & 55.7 & 145.0 & 77.3 \\
\hline \multicolumn{2}{|c|}{ AÖF (0.01) (Y) } & - & - & 0.8 & - & - & 13.7 \\
\hline \multicolumn{2}{|c|}{ AÖF (0.01) (GxY) } & - & - & 6.2 & - & - & 109.3 \\
\hline \multicolumn{2}{|c|}{$\begin{array}{l}\text { Varyasyon Katsayıs1 } \\
(\%)\end{array}$} & 6.5 & 10.8 & 9.3 & 8.1 & 11.8 & 11.5 \\
\hline
\end{tabular}

Aynı harf ile işaretli ortalamalar farksızdır. ** ile işaretli F değerleri 0.01 ihtimal düzeyinde önemlidir

Bin tane ağırlı̆̆ı en düşük genotip Sultan 95 (22.1 g) olmuş, Alparslan (24.3 g), Köse 220/39 (25.0 g) ve Seri 82 $(25.0 \mathrm{~g}) 1000$ tane ağırlığı düşük diğer genotipler olarak Sultan 95 çeşidini izlemiştir. Bin tane ağırlığı yönünden genotipler arasındaki varyasyon 2010-11 ürün yılında daha dar sınırlar içerisinde kalmış, en yüksek 1000 tane ağırlığı Hawk (45.2 g) çeşidinde tespit edilmiştir. Ak Buğday (44.4 g), Sert Buğday (44.3 g), Zencirci 2002 (44.0 g), Conkesme (44.0 g) ve Sürak 1593/51 (44.0 g) 1000 tane ağırlığı yüksek diğer genotipler olmuşlardır. En düşük 1000 tane ağırlıkları ise Doğankent 1 (31.6 g), Kate A-1 (32.1 g) ve Orso (32.2 g) genotiplerinde hesaplanmıştır. Ürün yılları ortalaması olarak en yüksek 1000 tane ağırlıkları Sönmez 2001 (43.3 g), Tir (43.2 g), Sürak 1593/51 (42.6 g) ve Zencirci 2002 (41.2 g); en düşük 1000 tane ağırlıkları ise Alparslan (28.9 g), Doğankent 1 (30.0 g) ve Köse 220/39 (31.7 g) genotiplerinde tespit edilmiştir (Çizelge 4). Buğday genotiplerinin bin tane ağırlıkları Erzurum koşullarında Çağlar ve ark. (2006) tarafindan 34.1-42.5 g, Öztürk ve Akkaya (1996) tarafından 37.4-46.8 g, Konya koşullarında Soylu ve ark. (1999) tarafindan 32.9-46.8 g arasında belirlenmiş, genotipler arasındaki farkların önemli olduğuna dikkat çekilmiştir. Tane ağırlığı kardeşlenme derecesi ve $\mathrm{m}^{2}$ 'deki başak sayısı, başaktaki tane sayısı, yaprak alanı ve yaprak alanı süresi gibi çok sayıda fizyolojik süreç tarafından etkilenmektedir. Bu fizyolojik olayların ürün yıllarına ve çeşitlere göre farklı seyretmesi, 1000 tane ağırlığının da farklı olmasına neden olmaktadır (Öztürk ve ark. 2011).

Tane verimi yönünden buğday genotipleri arasındaki farkların iki ürün yılında ve ürün yılları ortalaması olarak önemli olduğu tespit edilmiştir. Tane verimi üzerine ürün yıllarının etkisi de önemli olmuş, genotiplerin ortalaması olarak 2009-10 ürün yılında (372.0 kg/da), 2010-11 ürün yılına $(667.5 \mathrm{~kg} / \mathrm{da})$ göre önemli derecede düşük tane verimi elde edilmiştir. Hem ilkbahar geç don olayı nedeni ile başaktaki tane sayısının, hem de şiddetli sarı pas enfeksiyonu nedeni ile tane ağırlığının azalması, 2009-10 ürün yılında tane veriminin önemli derecede 
düşük olmasına neden olmuştur. Ayrıca, ikinci ürün yılında özellikle verimin belirlendiği büyüme ve gelişme dönemlerinde (Nisan, Mayıs), ilk yıla göre daha fazla yağış düşmesi de tane veriminde önemli derecede artış sağlamıştır. Genotiplerin tane verimi yönünden sıralanışı yıllara göre farklılık göstermiş ve "genotip x yıl”" interaksiyonu önemli çıkmıştır (Çizelge 4).

Genotiplerin tane verimleri 2009-10 ürün yılında 209.3-650.1 kg/da, 2010-11 ürün yılında 191.4-1136.7 kg/da, ürün yıllarının ortalaması olarak ise $213.5-756.8 \mathrm{~kg} / \mathrm{da}$ arasında değişim göstermiştir. En yüksek tane verimi 2009-10 ürün y1lında Atlı 2002 çeşidinde $(650.1 \mathrm{~kg} / \mathrm{da})$ belirlenmiş ve bu çeşit diğer tüm genotiplerden üstün olmuştur. Bu çeşidi Lancer (591.4 kg/da) ve Sönmez $2001(552.7 \mathrm{~kg} / \mathrm{da})$ çeşitleri takip etmiştir. En düşük tane verimi Kırik çeşidinden (209.3 kg/da) elde edilmiş, onu Kılçıksız Buğday (218.8 kg/da), Köse 220/39 (219.1 kg/da) ve Ankara 093/44 (221.4 kg/da) çeşitleri izlemiştir. Son sırada yer alan Kırik çeşidi ile sıralamada 58. gelen Seri 82 çeşidi arasındaki fark önemli olmamıştır. Tane verimi yönünden 2010-11 ürün yılında Demir 2000 (1136.7 kg/da), Gün 91 (1047.2 kg/da), Kırgız 95 (1019.9 kg/da) ve Karahan 99 (1000.0 kg/da) çeşitleri ilk sıraları paylaşmışken; Pamukova 97, Kılçıksız Buğday, Seri 82 ve Doğankent 1 sırasıyla 192.4 kg/da, 208.2 $\mathrm{kg} / \mathrm{da}, 243.9 \mathrm{~kg} / \mathrm{da}$ ve $299.7 \mathrm{~kg} / \mathrm{da}$ tane verimleri ile son sıralarda yer almışlardır. Bu ürün yılında Pamukova 97 $(278.8 \mathrm{~kg} / \mathrm{da})$, Seri $82(321.3 \mathrm{~kg} / \mathrm{da})$ ve Doğankent $1(446.3 \mathrm{~kg} / \mathrm{da})$ çeşitlerinin $\mathrm{m}^{2}$ ' deki başak sayısı yönünden de son sıralarda yer almaları dikkat çekmiştir. Ürün yıllarının ortalaması olarak en yüksek tane verimi Demir $2000(756.8 \mathrm{~kg} / \mathrm{da})$ çeşidinden elde edilmiş, bu çeşidi azalan tane verimleri ile Atlı 2002 (756.3 kg/da), Karahan $99(710.1 \mathrm{~kg} / \mathrm{da})$, Doğu $88(708.8 \mathrm{~kg} / \mathrm{da})$ ve Türkmen $(701.5 \mathrm{~kg} / \mathrm{da})$ çeşitleri izlemiştir. En düşük tane verimleri ise Kılçıksız Buğday (213.5 kg/da), Seri 82 (244.2 kg/da), Kırik (271.5 kg/da), Pamukova 97 (273.5 kg/da) ve Kırmızı Yerli (288.9 kg/da) genotiplerinde tespit edilmiştir (Çizelge 4). Erzurum koşullarında 12 kışlık buğday genotipinin adaptasyonunu araştıran Öztürk ve Akkaya (1996), genotiplerin tane verimlerinin 231.5-425.2 kg/da arasında değişim gösterdiğini, en yüksek tane veriminin Doğu 88 çeşidinden elde edildiğini bildirmişlerdir. Çağlar ve ark. (2006), Erzurum koşullarında 25 adet ekmeklik buğday çeşidinin adaptasyonunu araştırdıkları çalışmada, Doğu Anadolu Bölgesi için geliştirilmiş Doğu 88 çeşidinin en yüksek tane verimine (460.7 kg/da) sahip olduğunu, en düşük verimin ise Kırkpınar 79 çeşidinden $(302.4 \mathrm{~kg} / \mathrm{da})$ elde edildiğini bildirmişlerdir. Aydemir ve ark. (2001) tarafından 2001 yılı milli çeşit listesinde yer alan ekmeklik buğdayların bölgeler bazında verim ve kalite yönünden incelendiği çalışmada, Doğu Anadolu Bölgesi’nde kullanılan çeşitlerin tane verimlerinin $310.1-390.5 \mathrm{~kg} / \mathrm{da}$ arasında değiştiği bildirilmiştir.

Buğday genotiplerinin gerçekleşen tane verimleri; verim potansiyeli, iklim koşulları, kışa dayanıklılık, kurağa dayanıklılık ve hastalıklara dayanıklılık gibi çok sayıda faktör tarafından etkilenmektedir (Öztürk ve ark. 2011). $\mathrm{Bu}$ faktörlerin genotiplere veya ürün yıllarına göre farklı olabilmesi, tane veriminin de genotiplere veya ürün yıllarına göre farklı olmasına neden olmaktadır.

\section{Incelenen Karakterler Arasındaki İlişkiler ve Biplot Analizi}

Verim unsurları ile tane verimi arasındaki ilişkileri incelemek için ürün yılları ortalaması üzerinden hesaplanan basit korelasyon katsayıları Çizelge 5 'te verilmiştir. İlgili tablodan görüleceği gibi, üç ana verim unsuru ( ${ }^{2}{ }^{2}$ deki başak sayısı, başaktaki tane sayısı, bin tane ağırlığı) ile tane verimi arasındaki ilişkiler olumlu ve önemli olmuştur. Korelasyon analizi sonuçlarına göre tane verimi, en fazla $\mathrm{m}^{2}$ ' deki başak sayısı tarafından etkilenmiştir. Bunu sırasıyla başaktaki tane sayısı ve 1000 tane ağırlığı izlemiştir. Tane verimi üzerine en yüksek etkiyi m²'deki başak sayısı ve başaktaki tane sayısının yaptığı, tane ağırlığının etkisinin ise daha düşük düzeyde olduğu sonucu, çoğu araştırmacının bulguları ile benzerlik göstermektedir (Garcia del Moral ve ark. 1991; Demir ve Tosun 1991; Sönmez ve ark. 1999).

Biplot grafiği, genotiplerin daha net görülmesi ve değerlendirilmesi açısından büyük kolaylık sağlamaktadır. PC1 (1. ana bileşen) ve PC2 (2. ana bileşen), biplotu oluşturmak için kullanılan iki temel bileşendir. İki ürün yılının ortalama değerleriyle yapılan biplot analizinde, toplam varyansın (\%73.05), \%49.00'u birinci temel bileşenle, \%24.04'ü ise ikinci temel bileşenle açıklanmıştır (Şekil 1).

Genotipler açısından biplot grafiğine bakıldığında, PC1 $>0$ olan genotipler yüksek verimli ve $\mathrm{PC} 1<0$ olan genotipler düşük verimli olarak tanımlanmaktadır. PC2 değerleri ise stabilite ile ilişkilidir. PC2 değeri sıfıra yakın olan genotipler, uzak olanlara göre daha stabil olarak tanımlanmıştır (Kaya ve ark. 2006).

Araştırmanın yürütüldüğü ürün yıllarının ortalamalarıyla oluşturulan grafikte PC2 sıfır çizgisine yakın olan genotiplerin incelenen karakterler bakımından diğer genotiplere göre daha stabil olduğu söylenebilir. Buna göre, tane verimi yönünden dördüncü yüksek değere sahip olan 13 numaralı genotipin (Doğu 88) diğer genotiplere göre verim yönünden daha stabil olduğu belirlenmiştir. Vektörlerin merkezine en yakın olan ve araştırmada kontrol çeşidi olarak kullanılan 64 numaralı genotipin (Karasu 90) ise incelenen tüm karakterler yönünden 
ortalama değere sahip ve stabil olduğu görülmüştür (Şekil 1). Biplot grafiğinde, incelenen karakterler arasındaki korelasyonun olumlu ve önemli olmasından (Çizelge 5) dolayı karakterlere ait vektörler arasındaki açı 90 dereceden düşük olmuş ve vektörler aynı yönde toplanmıştır. PC2 eksenine daha yakın olan m² ${ }^{2}$ deki başak sayısı ve tane veriminin, başaktaki tane sayısı ve bin tane ağırlığına göre daha stabil oldukları belirlenmiştir (Şekil 1). Araştırmada kullanılan genotiplere göre incelenen karakterler üç ana gruba ayrılmış ve genotiplerin dağılımları farklılık göstermiştir. İncelenen karakterlerden $\mathrm{m}^{2}$ 'deki başak sayısının tane verimine çok yakın olduğu ve tane verimi ile aynı grupta yer aldığı, başaktaki tane sayısı ve bin tane ağırlığının ise ayrı gruplar oluşturduğu fakat tane verimiyle aynı yönde olduğu görülmüştür (Şekil 2). İncelenen tüm karakterler bakımından araştırmada kullanılan diğer genotiplere göre daha stabil olan 4, 13, 18, 16, 64 numaralı genotiplerin ortalamanın üzerinde değere sahip olduğu ve Erzurum koşullarında iyi performans gösterdiği; 17, 26 ve 54 numaralı genotiplerin ise stabil olmalarına rağmen ortalamanın altında kaldığ 1 ve kötü performans gösterdiği belirlenmiştir (Şekil 3). Ayrıca merkeze yakın olan 4 numaralı genotipin temsili çevreye uygun en ideal genotip olduğu belirlenmiş, bunu sırasıyla 13, 18, 25 ve 39 numaralı genotipler takip etmiştir (Şekil 4).

Çizelge 5. Verim unsurları ile tane verimi arasındaki basit korelasyon katsayıları (r)

\begin{tabular}{lccc}
\hline Karakterler & Başaktaki tane sayısı & Bin tane ağırlığ & Tane verimi \\
\hline Metrekaredeki başak sayısı & 0,064 & 0,065 & $0,640^{* * *}$ \\
Başaktaki tane sayısı & & 0,043 & $0,545^{* * *}$ \\
Bin tane ağırlığı & & $0,333^{* *}$ \\
\hline
\end{tabular}

** işaretli katsayılar $0.01, * * *$ işaretli katsayılar 0.001 düzeyinde önemlidir $(\mathrm{n}=64)$

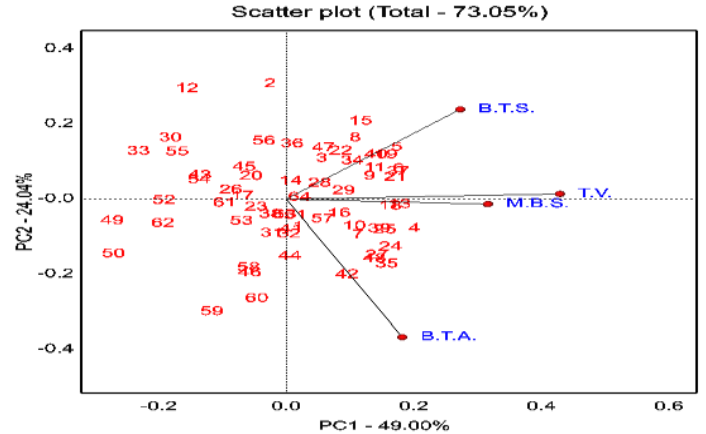

Şekil 1. İncelenen karakterlerin kendi aralarında ve genotipler ile olan ilişkisini gösteren biplot grafiği

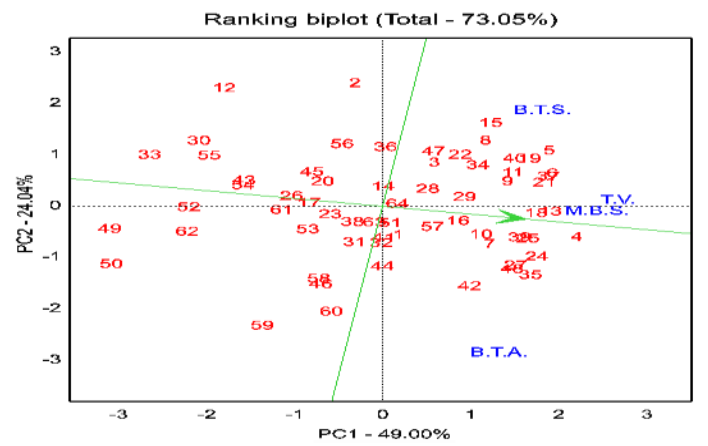

Şekil 3. İncelenen karakterler bakımından genotiplerin stabilitesi (Ranking biplot)

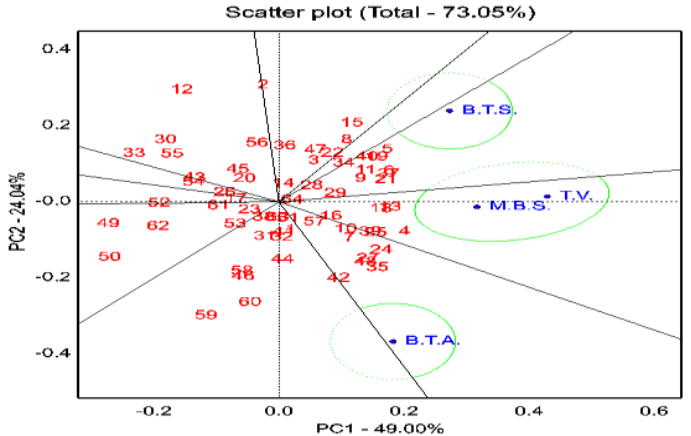

Şekil 2. Araştırmada incelenen karakterlerin gruplandirılması

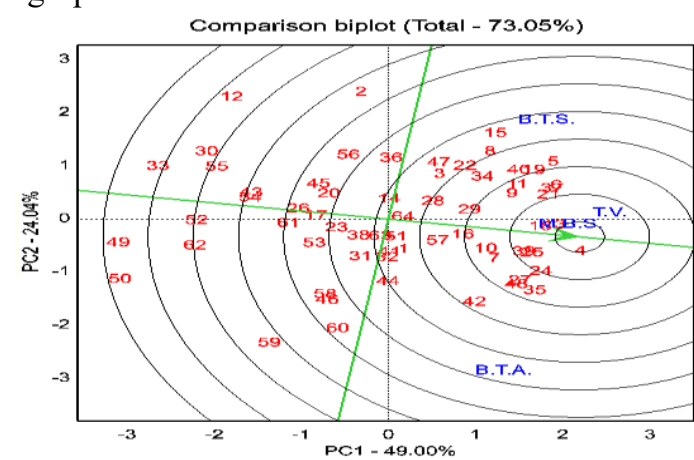

Şekil 4. İncelenen tüm karakterler bakımından öne çıkan genotiplerin belirlenmesi ve diğer genotiplerin durumu (Comparison biplot)

Erzurum ekolojik koşullarına uygun ve yüksek verimli çeşitlerin belirlenmesi amacıyla 64 ekmeklik buğday genotipinin iki yıl süreyle tane verimi ve verim unsurları yönünden değerlendirildiği bu araştırmada, incelenen karakterler yönünden buğday genotipleri arasında önemli farkların olduğu belirlenmiştir. İki ürün yılının ortalamasına göre tane verimi yönünden Demir 2000,Atlı 2002, Karahan 99, Doğu 88 ve Türkmen çeşitlerinin en yüksek değere sahip olduğu tespit edilmiştir. Yapılan korelasyon analizi sonucunda üç ana verim unsuru $\left(\mathrm{m}^{2}\right.$ 'deki başak sayısı, başaktaki tane sayısı, bin tane ağırlı̆̆ı) ile tane verimi arasındaki ilişkilerin olumlu ve 
önemli olduğu görülmüş̧ür. Biplot analizi sonucu oluşturulan grafiklere göre en stabil genotiplerin Atl1 2002, Doğu 88, İzgi 2001, Harmankaya 99 ve Karasu 90; en ideal genotiplerin ise Atlı 2002, Doğu 88, İzgi 2001, Lancer ve Türkmen olduğu belirlenmiştir. Alternatif karakterli Atlı 2002, kışlık karakterli İzgi 2001ve yöre için geliştirilen Doğu 88 çeşidinin hem stabil hem de Erzurum için en ideal genotipler olarak belirlendiği bu araştırma sonucunda, Atlı 2002 ve İzgi 2001 çeşitlerinin, yörede yüksek verim istikrarı gösteren Doğu 88 çeşidine alternatif olabileceği söylenebilir. Ayrıca, biplot analiz yöntemi ile oluşturulan iki yönlü grafiklerden faydalanılarak genotiplerin görsel olarak birçok karakter yönünden kolayca değerlendirilebildiği ve tüm karakterler bakımından yüksek performans gösteren genotiplerin daha kolay ve etkin bir şekilde belirlenebildiği sonucuna varılmıştır.

\section{Kaynaklar}

Altınbaş M, Bilgen G (1993). Bir ekmeklik buğday melezinde (T. aestivum L.) başak özelliklerinin verim için seçim ölçütü olarak değerlendirilmesi. Anadolu, Ege Tarımsal Araşt. Enst. Derg. 3(2): 70-88.

Aydemir T, Barut A, Yılmaz K, Sezer N (2001). 2001 yılı milli çeşit listesinde yer alan ekmeklik buğdayların bölgeler bazında verim ve kalite yönünden irdelenmesi. Türkiye 4. Tarla Bitkileri Kongresi, 17-21 Eylül, Tekirdağ, s. 37-44.

Bilgin O, Korkut KZ (2005). Bazı ekmeklik buğday (Triticum aestivum L.) çeşit ve hatlarının tane verimi ve bazı fenolojik özelliklerinin belirlenmesi. Tekirdağ Ziraat Fak. Derg. 2(1): 58-65.

Çağlar Ö, Öztürk A, Bulut S (2006). Bazı ekmeklik buğday çeşitlerinin Erzurum Ovası koşullarına adaptasyonu. Atatürk Üniversitesi Ziraat Fakültesi Dergisi 37(1): 1-7.

Demir I, Tosun M (1991). Ekmeklik ve makarnalık buğdaylarda verim ve bazı verim komponentlerinin korelasyonu ve path analizi. Ege Zir. Fak. Derg. 28: 41-47.

Dokuyucu T, Cesurer L, Akkaya A (1999). Bazı ekmeklik buğday genotiplerinin Kahramanmaraş koşullarında verim ve verim unsurlarının incelenmesi. Türkiye 3. Tarla Bitkileri Kongresi, 15-20 Kasım, Adana, s. $127-132$.

Erekul O, Köhn W (2006). Effect of weather and soil conditions on yield components and bread-making quality of winter wheat (Triticum aestivumL.) and winter triticale (Triticosecale Wittm.) varieties in North-East Germany. J. Agronomy and Crop Science 192: 452-464.

Ergene A (1993). Toprak Biliminin Esasları. Atatürk Üniv. Ziraat Fak. Yayın No: 267, Ders Kitapları Serisi No: 42, $560 \mathrm{~s}$, Erzurum.

FAO (2017). Production Yearbook. http://www.fao.org/faostat/en/\#data/QC (Erişim tarihi: 27 Nisan, 2017).

Garcia del Moral LF, Ramos JM, Garcia del Moral MB, Jimenez-Tejada MP (1991). Ontogenetic approach to grain production in spring barley based on path coefficient analysis. Crop Science 31: 1179-1185.

Gebeyehou G, Knott DR, Baker RJ (1982). Relationships among durations of vegetative and grain filling phases, yield components, and grain yield in durum wheat cultivars. Crop Science 22: 287-290.

Harrel DM, Wilhelm WW, McMaster GS, (1993). Scales: A computer program to convert among three developmental stage scales for wheat. Agron. J. 85: 758-763.

Kaya Y, Akçura M, Taner S (2006). GGE-biplot analysis of multi-environment yield trials in bread wheat. Turkish Journal of Agriculture and Forestry 30: 325-337.

Korkut KZ, Başer İ, Bilir S (1993). Makarnalık buğdaylarda korelasyon ve path katsayıları üzerine çalışmalar. Makarnalık Buğday ve Mamulleri Sempozyumu, 30 Kasım-3 Aralık, Ankara, s. 183-187.

Korkut KZ, Ünay A (1987). Tahıllarda başak taslağı gelişimi ile verim öğeleri arasındaki ilişkiler üzerine araştırmalar. TÜBİTAK, Türkiye Tahıl Sempozyumu, 6-9 Ekim, Bursa, s. 329-336.

Özen S, Akman Z (2015). Yozgat ekolojik koşullarında bazı ekmeklik buğday çeşitlerinin verim ve kalite özelliklerinin belirlenmesi. Süleyman Demirel Üniv. Ziraat Fak. Dergisi 10(1): 35-43.

Öztürk A (1999). Kuraklığın kışlık buğdayın gelişmesi ve verimine etkisi. Turk J. Agric. For. 23 (5): 531-540.

Öztürk A, Akkaya A (1996). Kışlık buğday genotiplerinde tane verimi, verim unsurları ve fenolojik dönemler üzerine bir araştırma. Atatürk Üniversitesi Ziraat Fakültesi Dergisi 27: 187-202.

Öztürk A, Akten Ş (1999). Kışlık buğdayda bazı morfofizyolojik karakterler ve tane verimine etkileri. Tr. J. of Agriculture and Forestry 23 (Ek say1 2): 409-422.

Öztürk A, Çağlar Ö, Aydın M, Bayram S (2011). Ekmeklik buğday genotiplerinin erken gelişme dönemlerindeki kuraklığa dayanıklılık yönünden karakterizasyonu. TÜBİTAK Tovag Proje No: 108 O 511, Sonuç Raporu, $57 \mathrm{~s}$, Erzurum.

Peterson CJ, Graybosch RA, Boenziger PS, Grambacher AW (1992). Genotype and environment effects on quality characteristics of hard red winter wheat. Crop Science 32: 98-103.

Poehlman JM (1987). Breeding Field Crops. Van Nostr and Reinhold Company Inc. 115 Fifth Avenue New York.

Preiffer WH, Sayre KD, Payne TS (2001). Increasing durum wheat yield potential and yield stability. Proceeding of the Warren E. Kronstad Symposium CIMMYT, 15-17 March, pp. 120-123.

Simane B, Struik PC, Nachit MM, Peacock JM (1993). Ontogenetic analysis of yield components and yield 
stability of durum wheat in water-limited environments. Euphytica 71:211-219.

Soylu S, Topal A, Sade B, Akgün N (1999). Konya şartlarında bazı ekmeklik buğday çeşitlerinin verim ve verim öğelerinin belirlenmesi. S.Ü. Zir. Fak. Derg 13: 60-73.

Sönmez F, Ülker M, Yılmaz N, Ege H, Bürün B, Apak R (1999). Tir buğdayında tane verimi ile bazı verim öğeleri arasındaki ilişkiler. Turkish Journal of Agriculture and Forestry 23: 45-52.

Tosun O, Yurtman N (1973). Ekmeklik buğdaylarda (Triticum aestivumL.) verime etkili morfolojik ve fizyolojik özellikler. Ankara Üniversitesi Ziraat Fakültesi Y1llı̆̆ı 23: 418-434.

TÜIK (2017). Tarım İstatistikleri. http://www.tuik.gov.tr (Erişim: 27 Nisan, 2017).

Valerio IP, Carvalho FIF, Oliveira AC, Benin G, Souza VQ, Machado AA, Bertan I, Busato CC, Silveira G, Fonseca DAR (2009). Seeding density in wheat genotypes as a function of tillering potential. Sci. Agric. 66 (1): 28-39.

Walker KC, Matthews S (1991). Effect of autumn nitrogen and sowing date on the growth and yield of winter barley in the North of Scotland. Journal of Agricultural Sci. 117 (3): 279-285.

Wiegand CL, Gebermann AH, Cuellar JA (1981). Development and yield of hard red winter wheats under semitropical conditions. Agron. J. 73 (1): 29-37.

Yağdı K (2004). Bursa koşullarında geliştirilen ekmelik buğday hatlarının bazı kalite özelliklerinin araştırılması. Uludağ Üniv. Zir. Fak. Derg. 18: 11-23.

Yan W (2001). GGE biplot-A Windows application for graphical analysis of multi-environment trial data and other types two-way data. Agron. J. 93: 1111-1118.

Yan W, Tinker NA (2006). Biplot analysis of multi-environment trial data: Principles and applications. Can. J. Plant Sci. 86: 623-645.

Yan W, Kang MS, Ma B, Woods S, Cornelius PL (2007). GGE Biplot vs. AMMI analysis of genotype-byenvironment data. Crop Science 47: 643-655.

Yau SK (1995). Regression and AMMI analyses of genotype $x$ environment interactions: An empirical comparison. Agron. J. 87(1): 121-126. 